\title{
HENRY KEAZOR
}

\section{"Il beneficio delle statue" - Antikenrezeption in Guido Renis "Herkules"-Zyklus}

Obgleich wir über Guido Renis "Herkules"-Zyklus dank der dessen Entstehung begleitenden Korrespondenz zwischen seinem Auftraggeber, dem Herzog von Mantua, Ferdinando Gonzaga, und seinem Agenten in Bologna, Conte Andrea Barbazzi, erstaunlich gut informiert sind ${ }^{1}$, stellten und stellen die vier Gemälde dieser Themengruppe den sich mit innen befassenden Kunsthistoriker doch noch immer vor zahlreiche Fragen: so wissen wir zwar, daß Gonzaga ursprünglich vorhatte, Reni zur Ausführung von Freskenmalereien in seiner neuerrichteten Villa La Favorita in Mantua zu gewinnen - ein Auftrag, dem der Bologneser Meister 1617 (wohl in Anbetracht der soeben in Ravenna gemachten Erfahrungen) unter Verweis auf seine "infermità mortali"" auszuweichen verstand, indem er zugleich anbot, Kartons anzufertigen, die dann tatsächlich auch von Gehilfen in Wandmalereien umgesetzt wurden ${ }^{3}$; für welchen Saal die zugleich bestellten und gänzlich von der Hand Renis ausgeführten vier "Herkules"Gemälde $[A b b .5,8,10,14]$ ursprünglich bestimmt waren, ist jedoch unbekannt: erst für das Jahr 1627/28 - rund sechs Jahre nach der Vollendung des Zyklus - informieren uns Dokumente darüber, daß die vier Bilder sich nicht (wie zu erwarten) in der Villa La Favorita befinden, sondern in jenem Korridor des herzöglichen Palastes dei Ganzaga hängen, "che passa da S. Barbara in Castello"4. Da Reni jedoch über Ferdi- nandos Agenten Barbazzi in einem Brief vom 9. Januar 1619 während der Arbeit an dem zweiten Gemälde um eine Planskizze des Saales bat, in dem sowohl der Standort des bereits am 1. November 1617 vollendeten "Herkules auf dem Scheiterhaufen" (heute - wie die übrigen drei Gemälde - im Louvre zu Paris) $)^{5}$ als auch die Position der Fenster einzutragen wären ${ }^{6}$, scheint zumindestens der Künstler selbst noch davon ausgegangen zu sein, daß der Zyklus auf die vier Wände eines Saales in der Villa La Favorita verteilt werden sollte.

Möglicherweise von der Überlegung ausgehend, daß die in den 20 er Jahren abgeschlossene Bilderfolge erst einige Jahre nach ihrer Fertigstellung von ihrem ursprünglichen Bestimmungsort entfernt und in den Korridor umgehängt worden sein könnte ${ }^{7}$, stellte Veronika Birke 1988 unter Verweis auf die Tugendhaftigkeit des Protagonisten die Hypothese auf, daß der Zyklus ursprünglich Teil der Ausstattung des herzöglichen Hochzeitsgemaches gewesen sein könnte ${ }^{8}$ - obgleich sie sich hierbei auf ikonographische Vorläufer hätte berufen können ${ }^{9}$, wurde ihr im vorliegenden Fall unter Verweis auf die hier gegebene, diesbezüglich jedoch wenig adäquate, wenn auch zumeist unsichtbare Protagonistin der Bilderfolge widersprochen: denn tatsächlich stiftet erst die Figur der Deinaeira den ikonographischen Zusammenhang zwischen den einzel- 


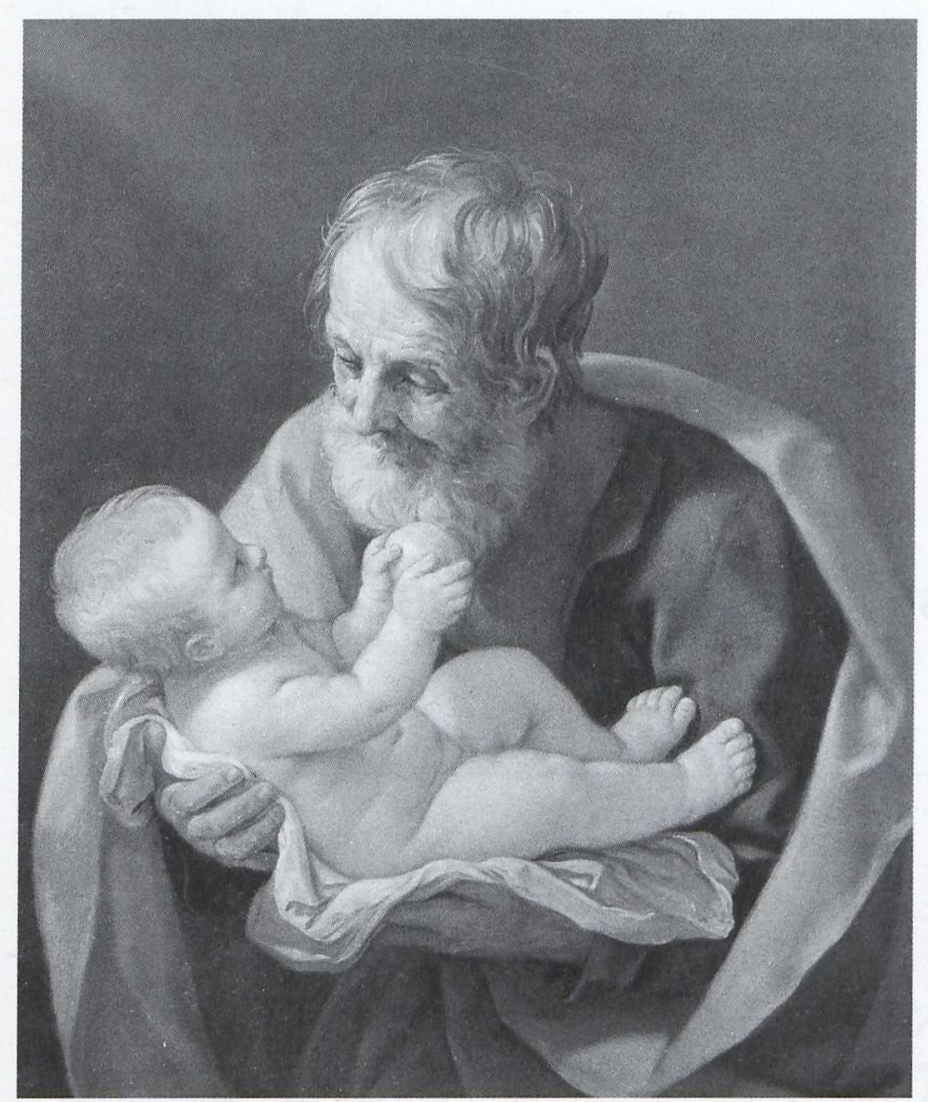

1) Guido Reni, «Heiliger Joseph». Privatbesitz, Houston.

nen Szenen. So nimmt Herkules den Kampf mit dem Flußgott Acheloos nur auf, um Deianeira für sich zu gewinnen; sie ist wiederum auch Anlaß der Feindschaft zwischen Herkules und Nessus, der sie - in dieser Szene einzig im ganzen Zyklus sichtbar - zu entführen versucht, von Herkules jedoch mit einem Pfeilschuß niedergestreckt wird. Der sterbende Kentaur nimmt daraufhin an beiden eine grausame Rache, indem er Deianeira vermeintlich das Rezept zu einem Herkules bestrickenden Liebestrank verrät, unter dessen Ingredienzen sich das Gift der zuvor von Herkules getöteten Hydra befindet. Als der tirynthische Held jedoch das von der Gattin in der Mixtur getränkte Gewand anlegt, wird er von der tatsächlich giftigen Tinktur bei lebendigem Leibe verzehrt - auf Geheiß des Orakels in Delphi besteigt er daraufhin einen Scheiterhaufen und verbrennt sich, nachdem Deianeira sich in ihrem Gram erhängt hat. Seine sterblichen Reste werden von Zeus in

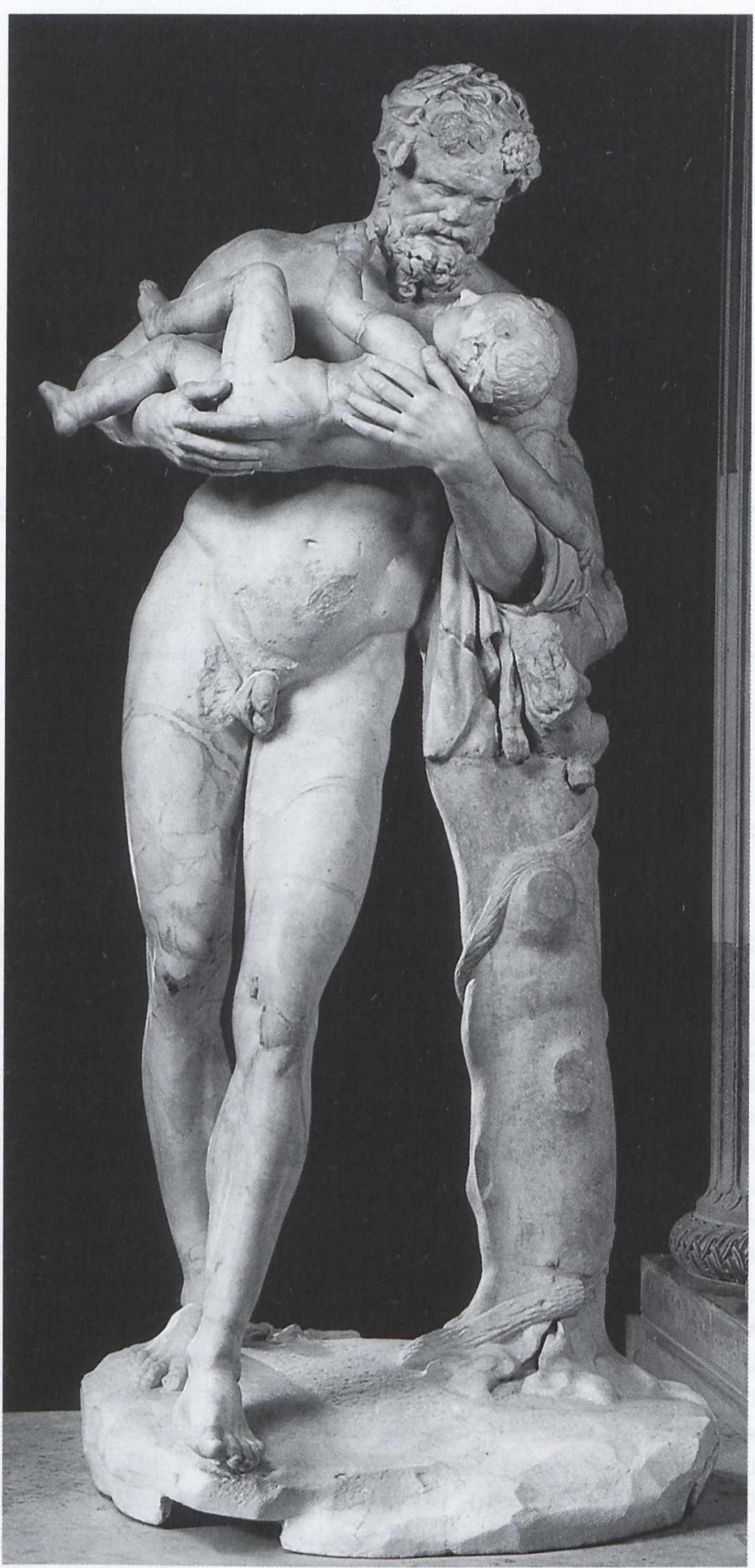

2) Antike Statue eines Silens mit kleinem Bacchus. Louvre, Paris. 


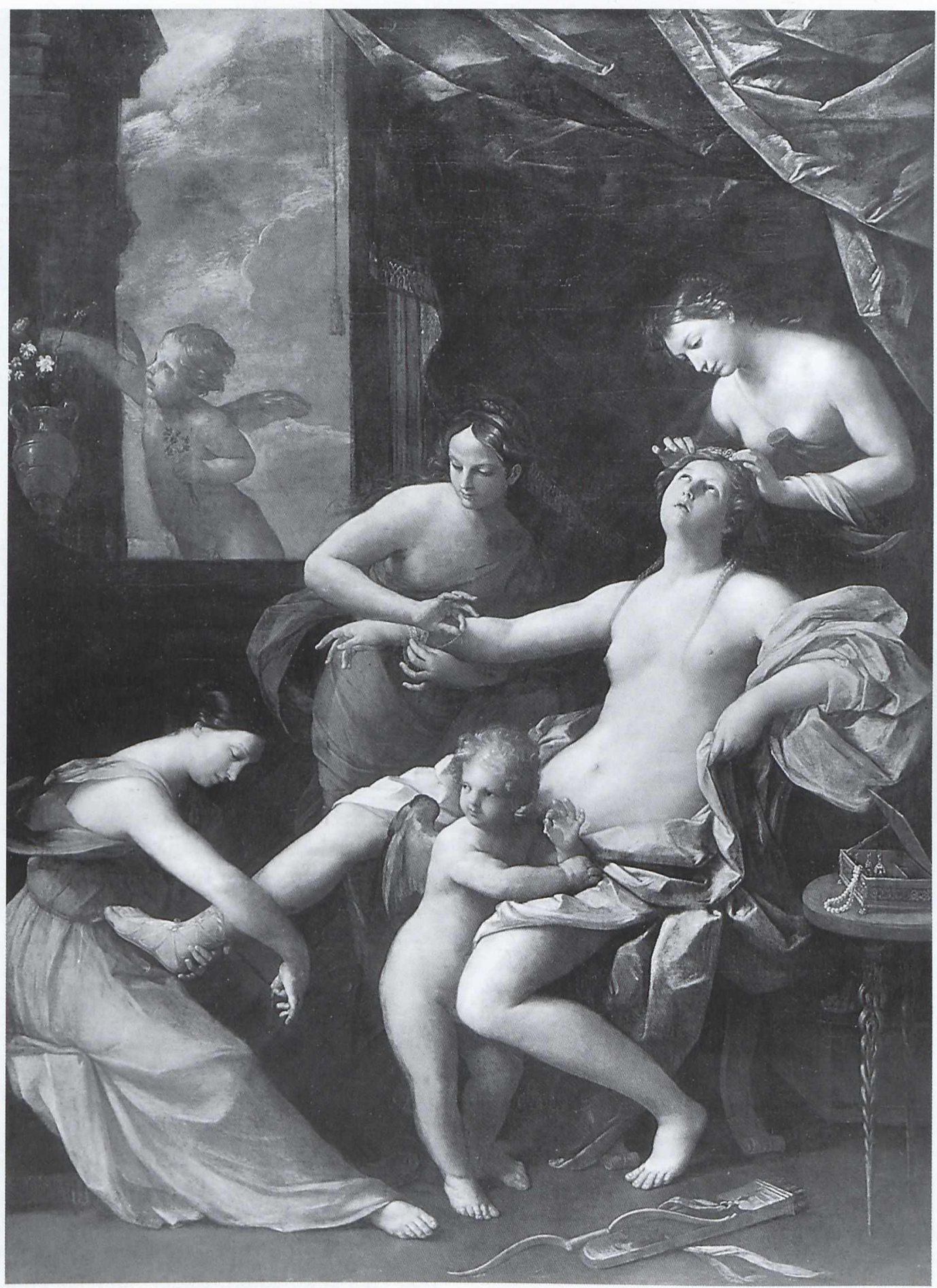

3) Guido Reni, «Toilette der Venus». National Gallery, London. 


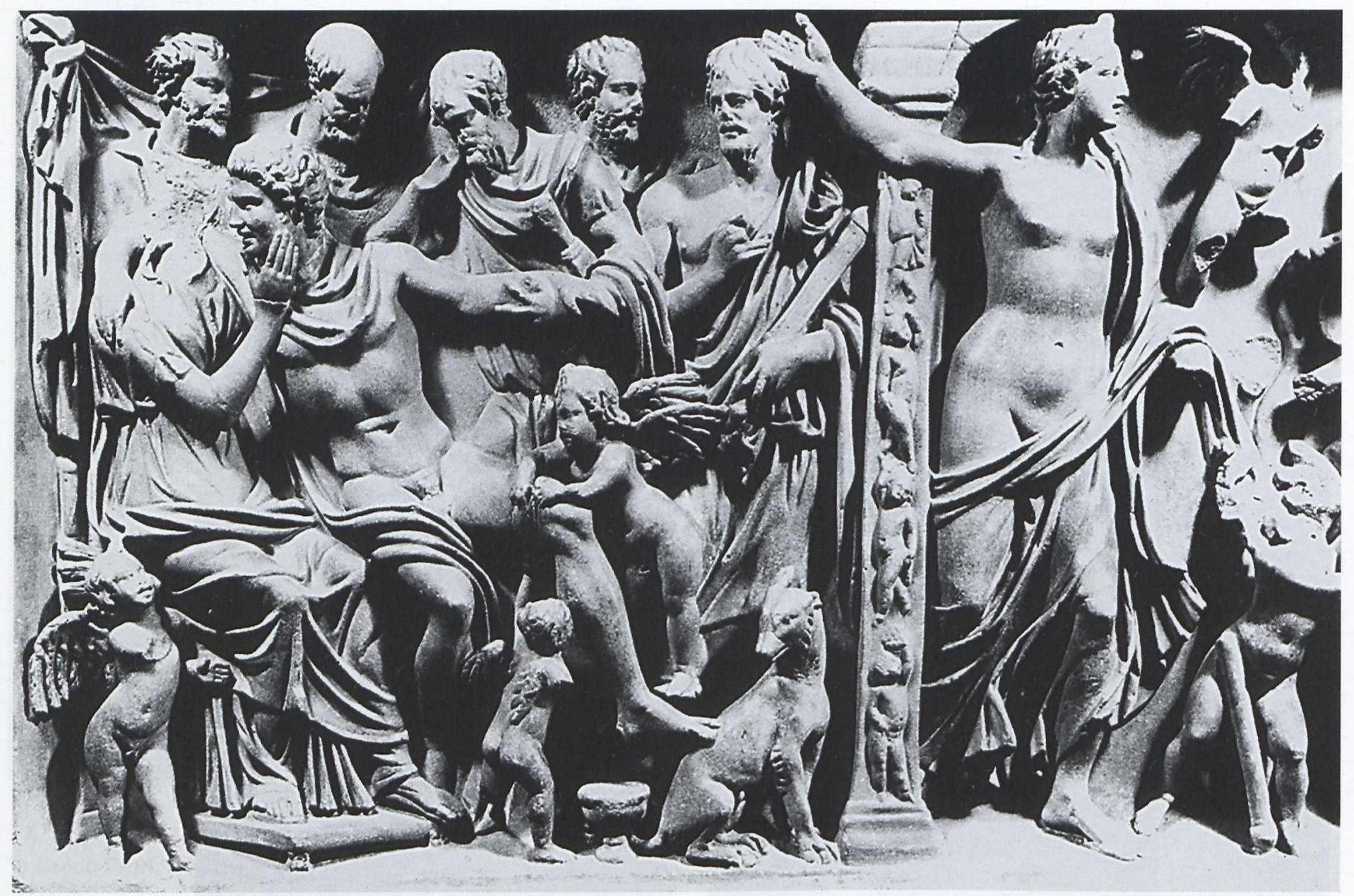

4) Adonis-Sarkophag. Palazzo Ducale, Mantua.

einem mächtigen Blitz getilgt, Herkules selbst als Sternbild an den Himmel versetzt. Trotz dieser letztendlichen Erhebung scheinen gerade die gewählten Szenen dieses um die Gestalt der Deianaira kreisenden Zyklus' angesichts ihrer Schuld am Tod ihres Gatten tatsächlich wenig zur mythologischen Überhöhung einer Hochzeit geeignet zu sein ${ }^{10}$, weshalb mittlerweile eine gleichfalls von Birke vorgeschlagene christologische Interpretation der Bilder bevorzugt wird ${ }^{11}$.

Jedoch nicht nur die Frage des Bestimmungsortes, sondern auch das Problem der Hängung der Gemälde hat viele Federn in Bewegung gesetzt: sich die oben erwähnte Bitte
Renis um eine die Fenstersituation aufnehmende Planskizze zum Vorwurf nehmend, haben mehrere Autoren versucht, den in den vier Bildern zu beobachtenden Lichteinfall zur Grundlage einer Rekonstruktion ihrer ursprünglichen Anordnung zu machen - es überrascht kaum, daß hierbei fast jeder Versuch zu einem eigenen, von den anderen Hypothesen abweichenden Ergebnis führt: hängt Veronika Birke 1988 die "Acheloos"und "Scheiterhaufen"-Bilder nebeneinander und damit den "Hydra"- und "Nessus"-Szenen gegenübergelegen, ordnet Ladislav Daniel 1992 die "Hydra"- und die "Scheiterhaufen"Szene als je von rechts beleuchtete Kompositionen nebenein- 


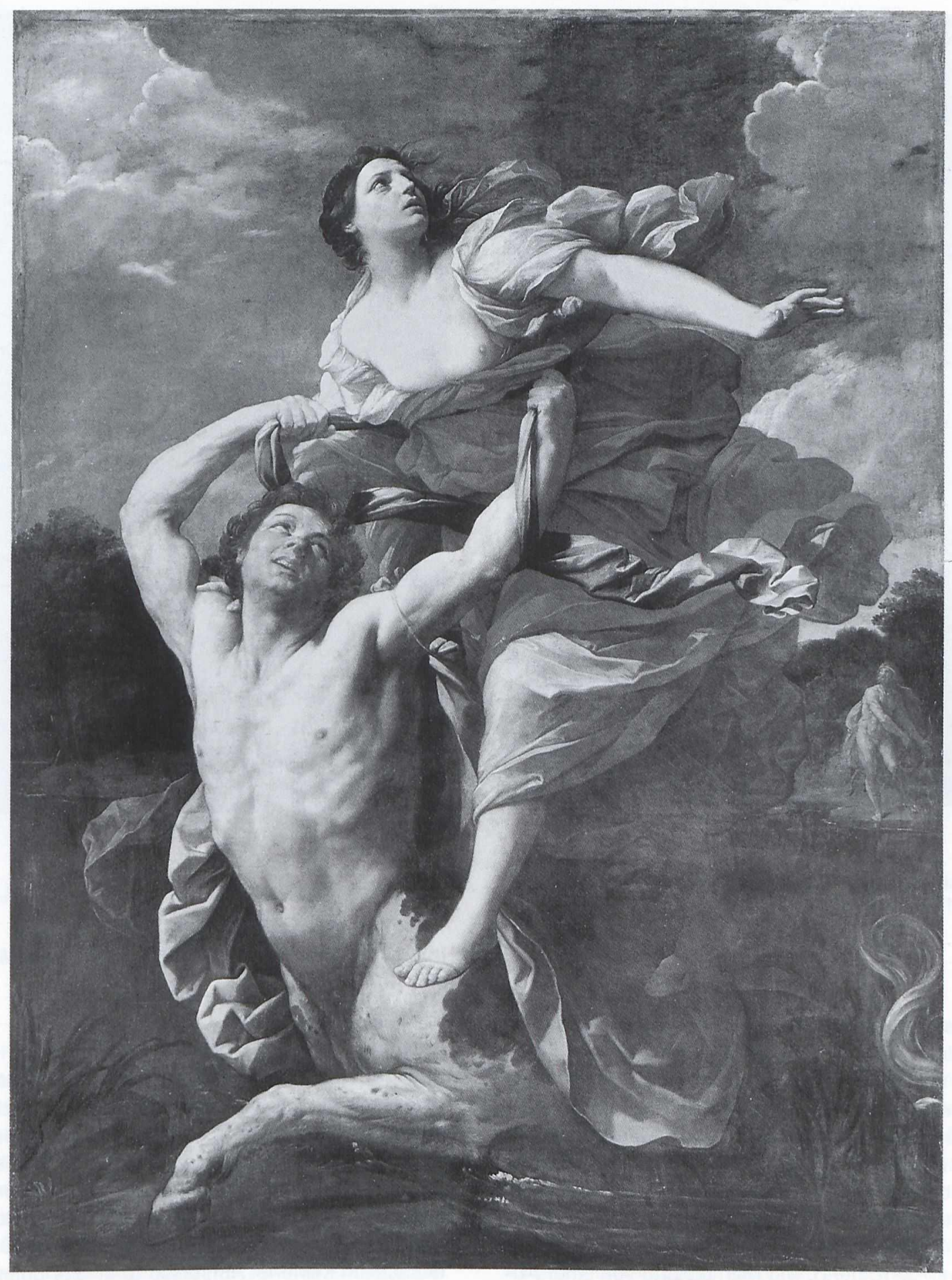

5) Guido Reni, «Nessus und Deianeira». Inv. 537, Louvre, Paris. 


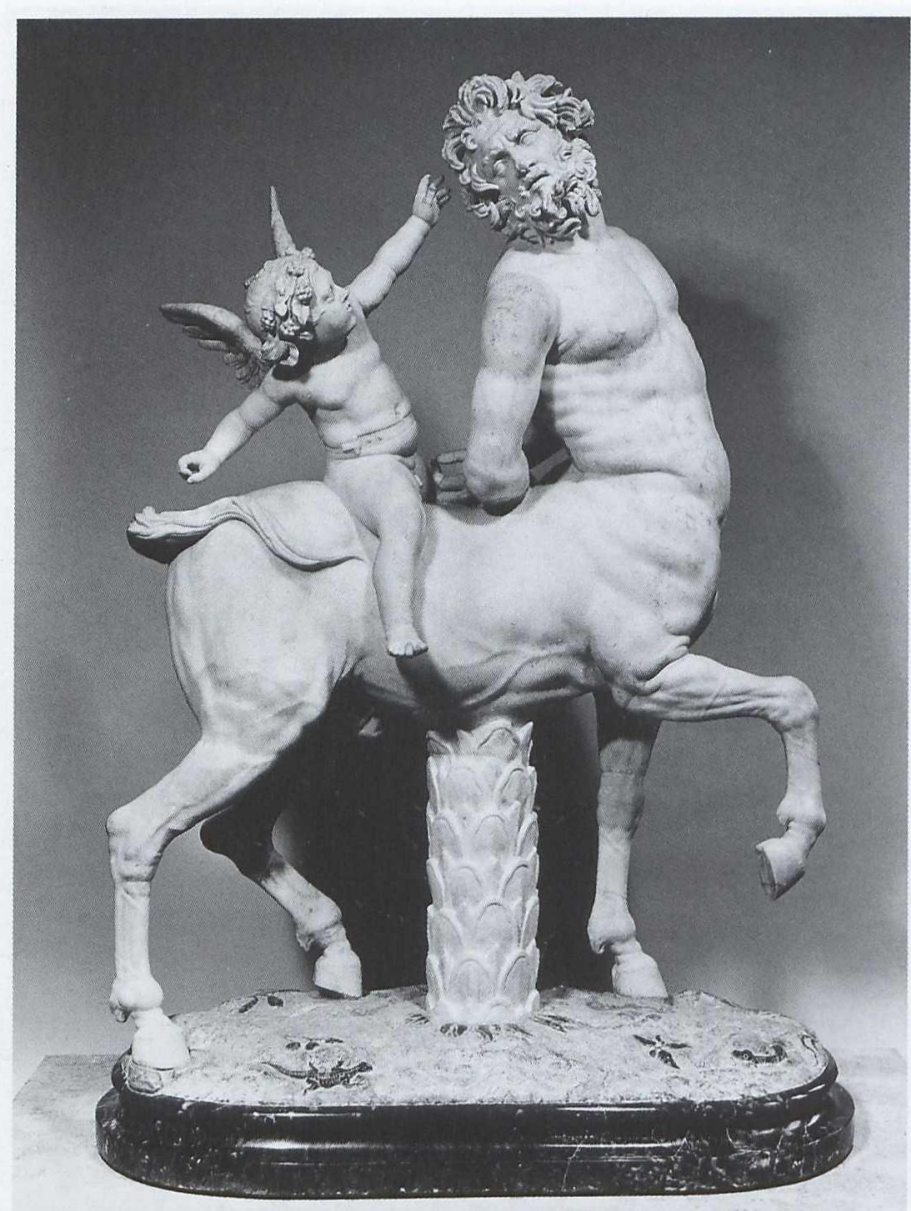

6) Borghese-Kentaur. Louvre, Paris.

ander an und stellt sie damit den je von links erhellten Szenen mit "Acheloos" und "Nessus" gegenüber"12.

Sind mithin also schon der Bestimmungsort, die Hängung und die Bedeutung der vier Gemälde Fragen unterworfen, so wurde seit den späten 80er Jahren unseres Jahrhunderts deutlich, daß sogar die bislang als sicher angenommene Chronologie von deren Ausführung korrekturbedürftig ist: der Publikation und Interpretation der von Braghirolli 1885 publizierten Dokumente vertrauend, war man bislang von einer $\mathrm{Ab}$ folge ausgegangen, an deren Beginn der um den 1. November 1617 vollendete und 9 Tage später verschickte "Herkules auf dem Scheiterhaufen" stand, worauf sodann im März und

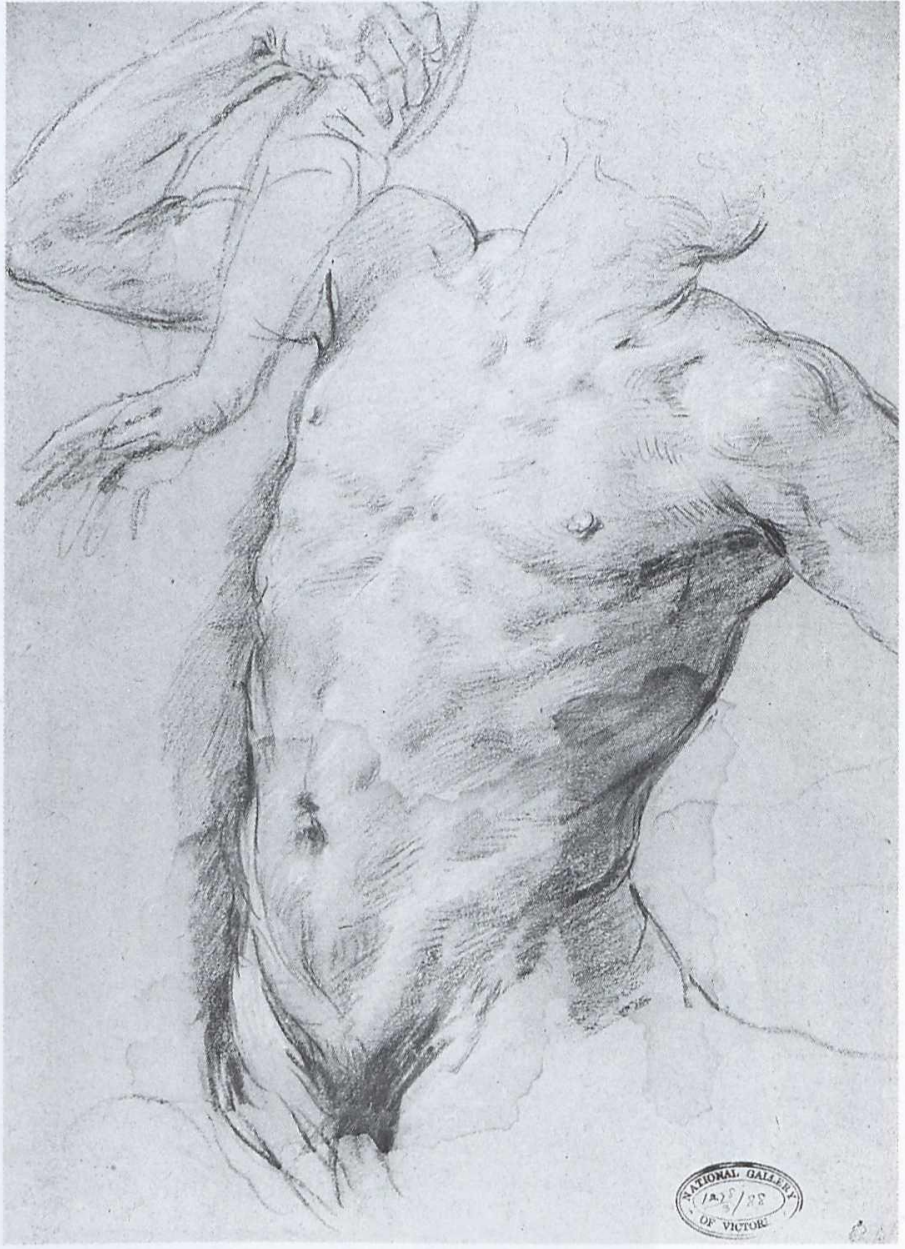

7) Guido Reni, Studienblatt für den Nessus.

Inv. 1278.3.88, National Gallery of Victoria, Melbourne.

September 1620 "Herkules und Acheloos" sowie "Herkules und die Hydra" folgten, während "Nessus und Deianeira" den Zyklus im April 1621 abzuschließen schienen ${ }^{13}$. Wie jedoch schon Pamela Askew 1978 zeigen konnte, ist aus aus dem Inhalt der zwischen Barbazzi und seinem Auftraggeber getauschten Briefe - die den "Herkules auf dem Scheiterhaufen" betreffenden Depeschen ausgenommen tatsächlich keinerlei Aufschluß über das Sujet der jeweils fertiggestellten und verschickten Werke zu gewinnen ${ }^{14}$. Darüberhinaus verspricht Barbazzi in besagtem Brief vom 22. April 1621 lediglich, in den nächsten Tagen ein Gemälde Renis 


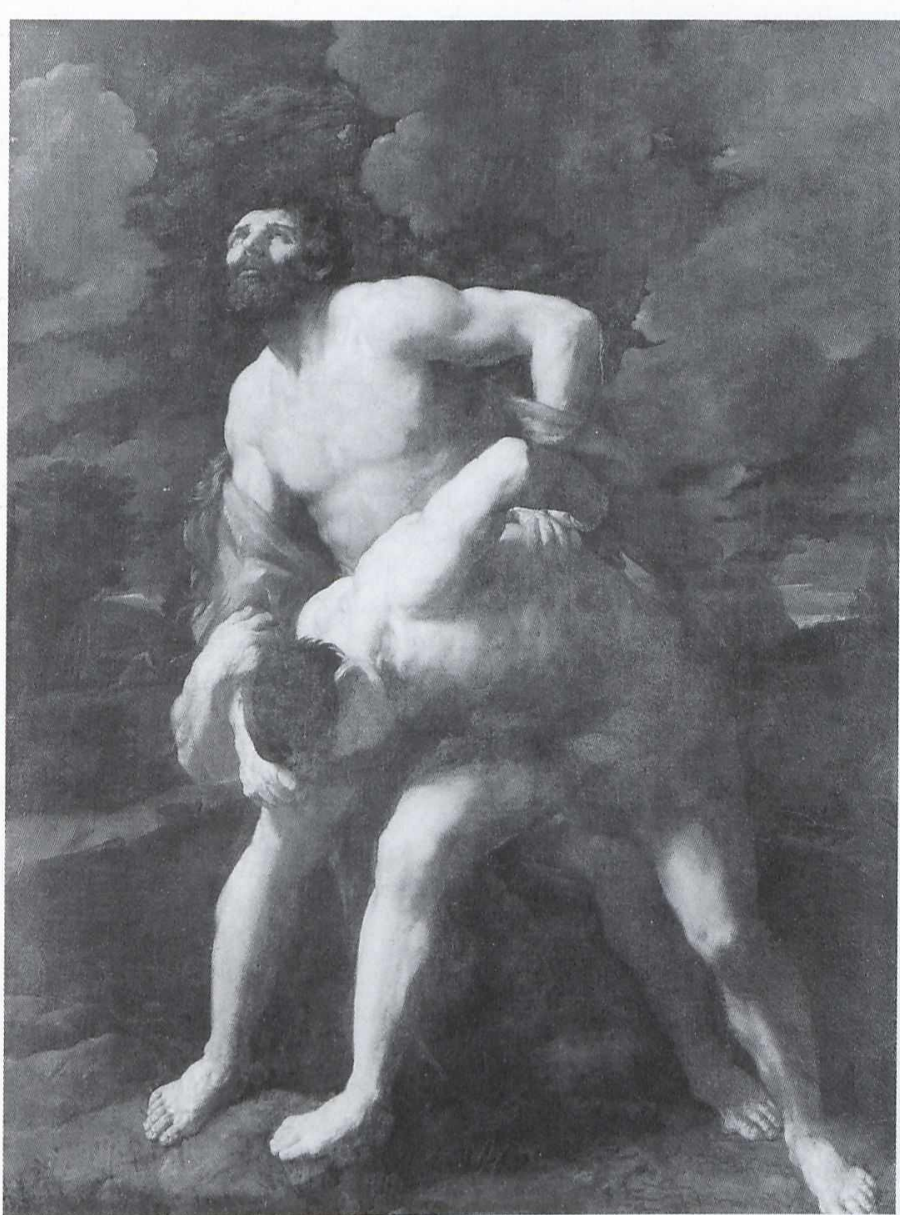

8) Guido Reni, «Herkules und Acheloos». Inv. 536, Paris, Louvre.

an seinen Herren abzuschicken - als wie wenig zuverlässig sich solche Versprechen jedoch erweisen konnten, zeigt ein weiterer Brief des Agenten vom 4. Januar 1623, in dem dieser sich bei Gonzaga dafür entschuldigt, daß er seine eigentliche Absicht, dem Schreiben ein Gemälde von der Hand Renis beizulegen, nicht in die Tat umsetzen könne, da die Maler wie Prokuratoren seien: "danno bone parole et cattivi fatti"15. Wie wenig bindend Renis Versprechen tatsächlich waren, zeigt sodann der Umstand, daß Barbazzi - auf die kommende Woche vertröstet - am 25. Januar (also tatsächlich erst fast drei Wochen später) noch immer mit leeren Händen dasitzt, obgleich er - gemeinsam mit dem Maler - nun eine gute

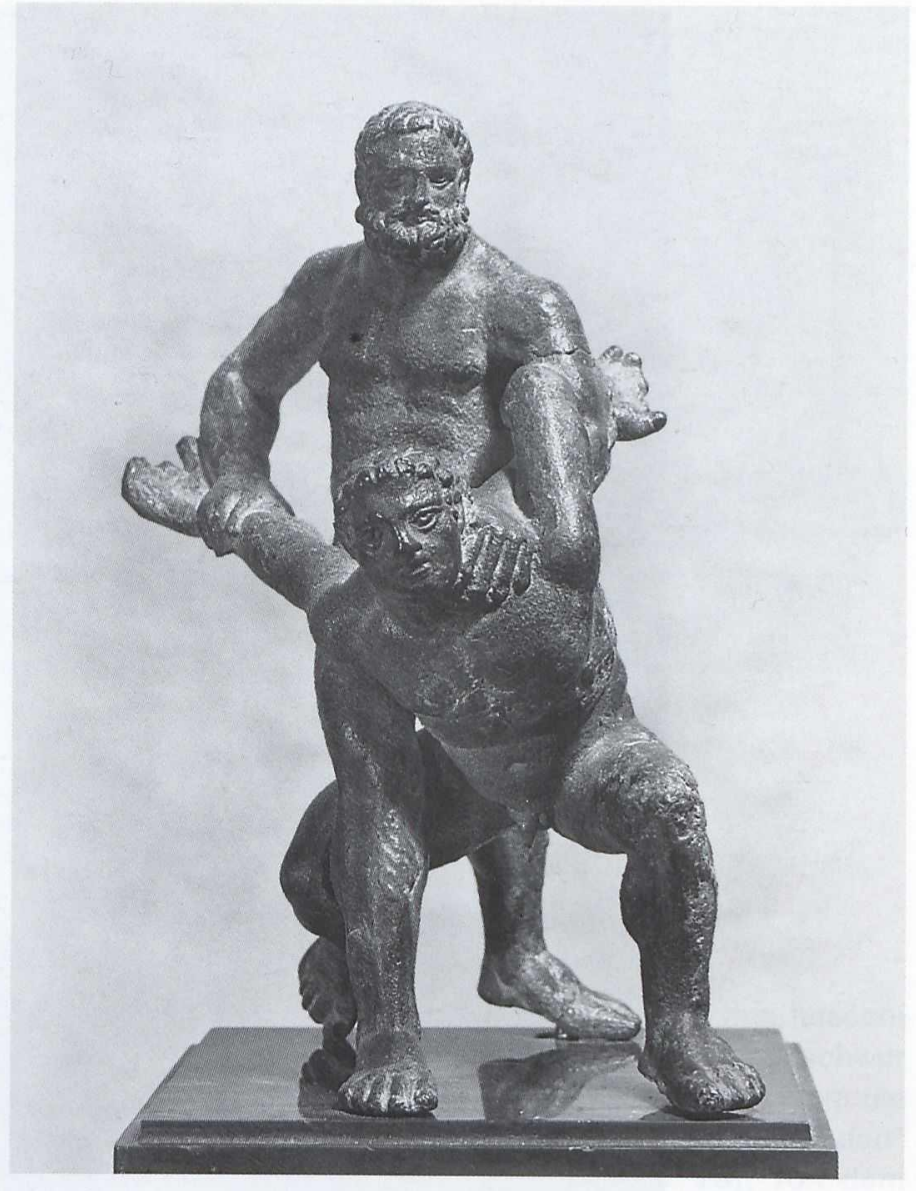

9) Hellenistische Athletengruppe. Glyptothek, München.

Entschuldigung vorweisen kann: Reni habe sich nicht aus Nachlässigkeit verspätet, sondern in dem Bestreben, das ausstehende Gemälde schöner zu gestalten: "nel più bello gli e venuto capricio di mutar tutta una figura et questo per migliorarla, il che è stata causa d'allungamento"16. Fast überflüssig zu sagen, daß Barbazzi - trotz Renis Zusage, das Bild eine Woche später auszuliefern - erst am 7. Juni 1623 (mithin sechs Monate später als ursprünglich vereinbart) melden konnte, daß er im Besitz des fertiggestellten Werkes sei ${ }^{17}$. Um welches Gemälde es sich hierbei handelte, geht aus den Schreiben nicht hervor, doch ist eine Verbindung mit der "Herkules"-Serie mehr als wahrscheinlich" ${ }^{18}$. Zwar ist man bislang von einem Abschluß der "Herkules"-Serie spätestens im 


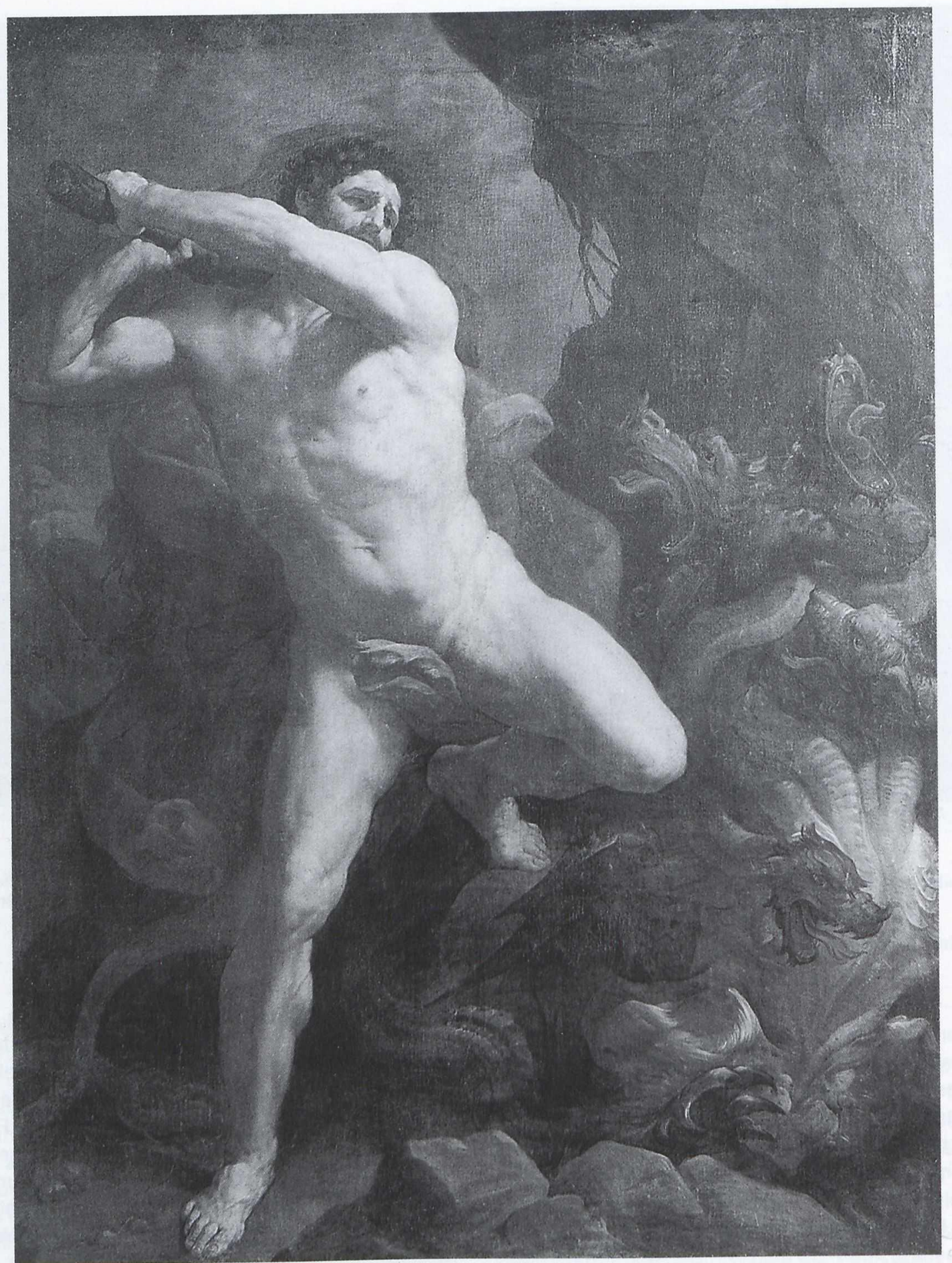

10) Guido Reni, «Herkules und die Hydra». Inv. 535, Louvre, Paris. 


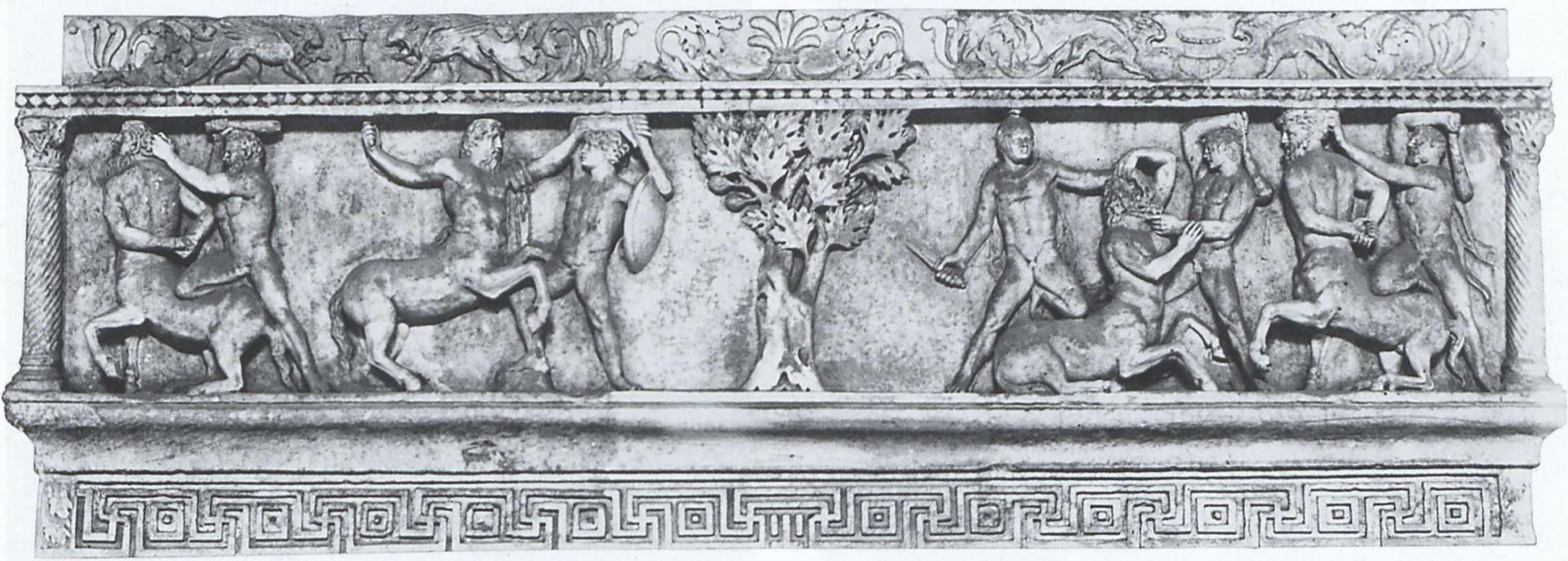

11) Sarkophag mit Zentauromachie. Sala delle Muse, Vatikan.

November 1622 ausgegangen ${ }^{19}$ - doch auch der diesbezüglich als Begründung herangezogene Dokumentenbefund hält einer eingehenden Prüfung nicht stand, besteht er doch lediglich in einem einzigen Satz Barbazzis, geschrieben am 16.11.1622, in dem dieser von den "Herkules"-Bildern in der Vergangenheitsform, d.h. als vollständig ausgeführtem Zyklus zu sprechen scheint - die dort benutzte Formulierung "li quadri che egli già fece a Sua Altezza delle Forze d'Hercole"20 läßt jedoch noch keinen zwingenden Rückschluß auf eine Vollendung des gesamten Zyklus zu diesem Zeitpunkt zu, da die "Herkules"-Bilder lediglich aufgrund der mit innen verbundenen, vorab getroffenen Preisvereinbarungen als Vergleichsfaktor herangezogen werden ${ }^{21}$.

Angesichts dieser vielen Fragezeichen mutet es fast tröstlich an, daß wenigstens hinsichtlich der von Guido Reni bei der Ausführung des sonst so rätselhaften Zyklus konsultierten Quellen und Vorbilder Klarheit zu herrschen scheint: so schrieb Giovanna degli Esposti 1988 in ihrem Katalogeintrag zu den Gonzaga-Bildern, für sie alle seien "facilmente individuabili i modelli della statuaria classica ed ellenistica ai quali Guido si ispirò". Und auch Otto Kurz äußerte bereits 1937 eher wegwerfend, die Figuren in den "Herkules"-Bildern seien "bloße in Pose gesetzte Modellabschriften - 'acadèmies' hätte man im 18. Jahrhundert gesagt"22. Daß Reni sich bei der
Konzeption der Posen seiner Bildprotagonisten nun tatsächlich eines bzw. mehrerer Modelle bedient hat, ist unschwer den vorbereitenden Zeichnungen abzulesen wie z.B. dem die ausgreifende Geste des "Herkules auf dem Scheiterhaufen" vorstudierenden Blatt in den Uffizien [Abb. 23], von dem Veronika Birke treffend geschrieben hat, daß es "die physische Unmittelbarkeit des Modells" widerspiegele ${ }^{23}$. Das antike Vorbild, nach dem Reni, gemäß der inm in der Akademie der Carracci vermittelten Praxis, das - uns sogar mit seinem Namen überlieferte ${ }^{24}$ - Modell setzte, scheint indes jedoch nicht ganz so "facilmente individuabile" zu sein, wie von degli Esposti formuliert, so daß eher Stéphane Loire recht zu geben ist, der 1996 bezüglich der eventuell von Reni für den gesamten Zyklus konsultierten antiken Vorbilder klagte: "Ici, encore nous manquons d'informations sur les modèles antiques que Reni avait à sa disposition lors de sa venue à Mantoue en 1617, ou même à Bologne (...)."25 Daß dieser sich bei der Planung der Gebärdendramaturgie seiner vier Gemälde ratund vorbildsuchend antiken Skulpturen zuwendete, ist angesichts der Bedeutung, die er dem an inn ergangenen Auftrag beimaß, sehr wahrscheinlich: nicht nur der oben zitierte Brief mit der — ihm leider nie erfüllten - Bitte um die Angabe der Beleuchtungssituation am Bestimmungsort, sondern auch die beträchtliche Zahl der erhaltenen Vorstudien ${ }^{26}$ zeigt, mit welch außergewöhnlicher Sorgfalt er die Ausführung der Gemälde 


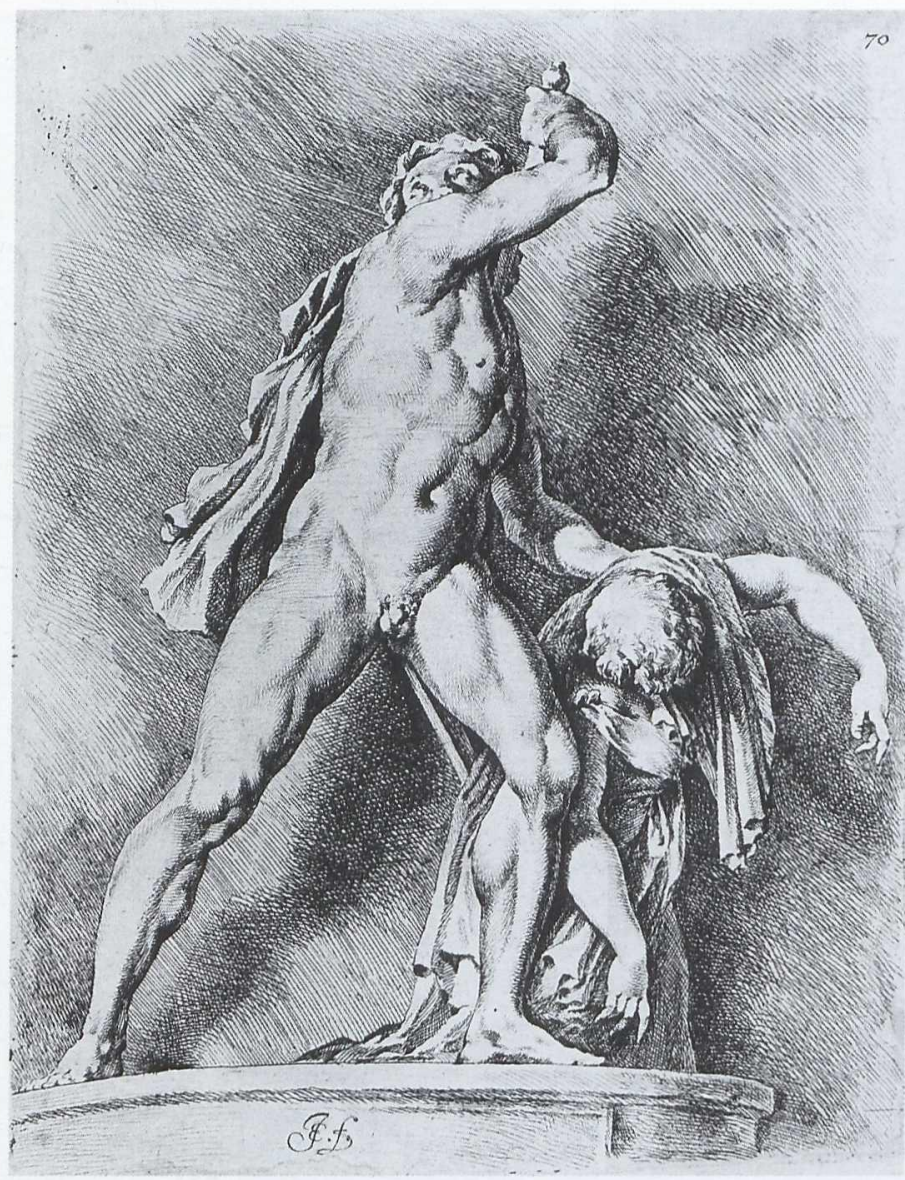

12) Tafel 70 von Jo. Episcopius, Signorum veterum Icones, s.I. 1671.

vorbereitete. Von den frühen Biographen Renis, Carlo Cesare Malvasia, Giovan Pietro Bellori und Giovanni Battista Passeri, wissen wir, welch großes Gewicht Reni dem "beneficio delle statue" 27 beimaß, von dem er zu profitieren suchte, indem er nicht nur "le belle teste delle statue antiche"28 studierte, sondern auch "procacciò ancora effigie nuove e caricatelle dalle medaglie greche antiche più singolari e da' più reconditi camei" 29 . Als sprechende Zeugen dieser produktiven Auseinandersetzung mit der Antike können nicht nur die bereits von Passeri und Bellori auf das Vorbild der Niobiden zurückgeführten, charakteristischen "alzate d'occhi" Renis ${ }^{30}$ aufgerufen werden, sondern auch Werke wie z.B. der "Heilige Joseph mit dem Christuskind" (Abb. 1: Houston, Privatbesitz) ${ }^{31}$, dessen

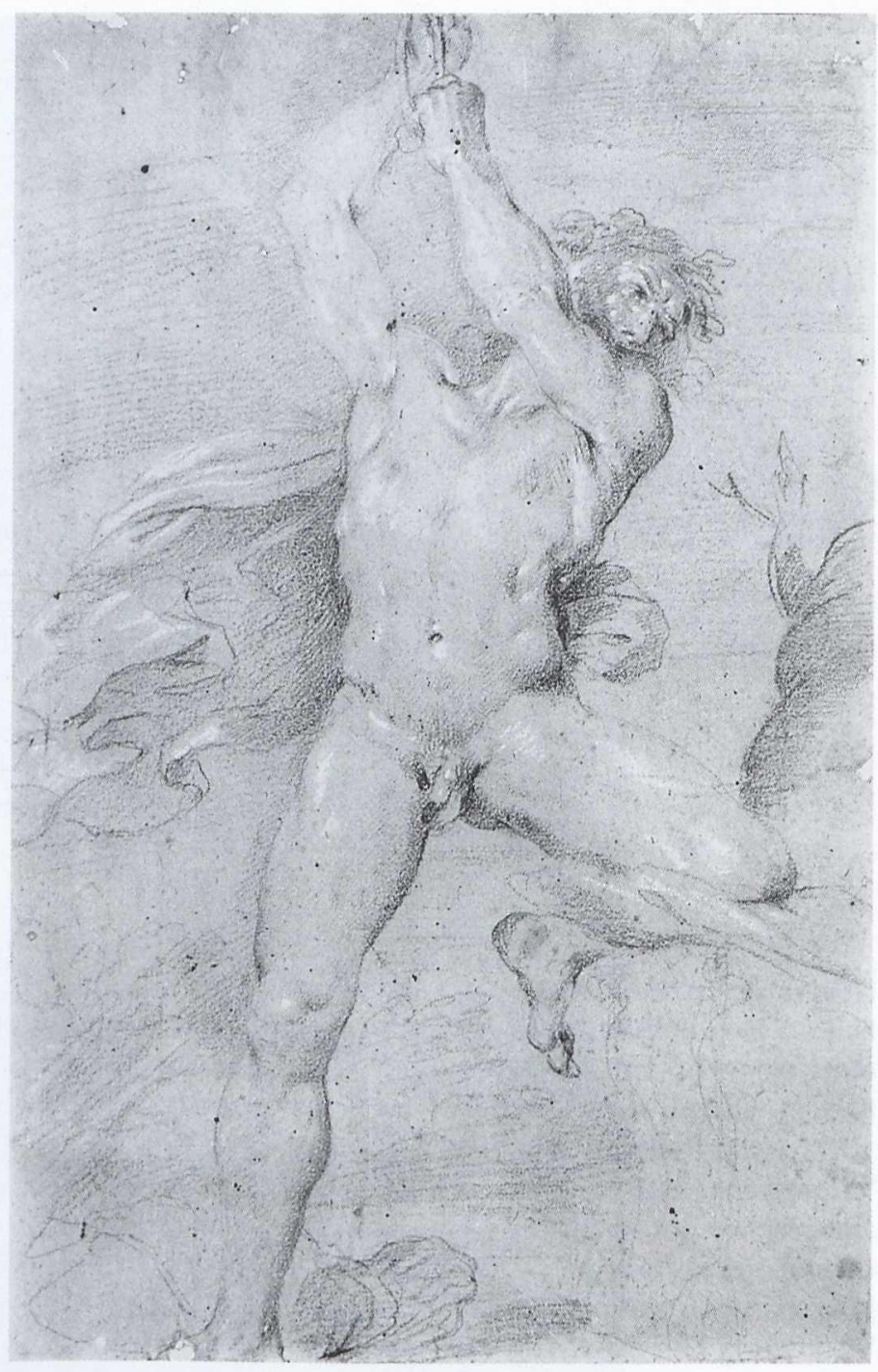

13) Gian Lorenzo Bernini, Zeichnung eines Kriegers. Louvre, Paris.

Komposition sich offenbar der antiken Bildgruppe eines Silen mit kleinem Bacchus (Abb. 2: Paris, Louvre) ${ }^{32}$ verdankt, während Renis "David mit dem Haupt des Goliath" (Paris, Louvre $)^{33}$ in seiner Pose dem Vorbild eines Flötespielenden Faunes (Rom, Musei Capitolini) ${ }^{34}$ folgt; mit der "Toilette der Venus" 35 schließlich (Abb. 3: einem 1622 bezeichnenderweise gleichfalls für Ferdinando Gonzaga ausgeführten Werk; 


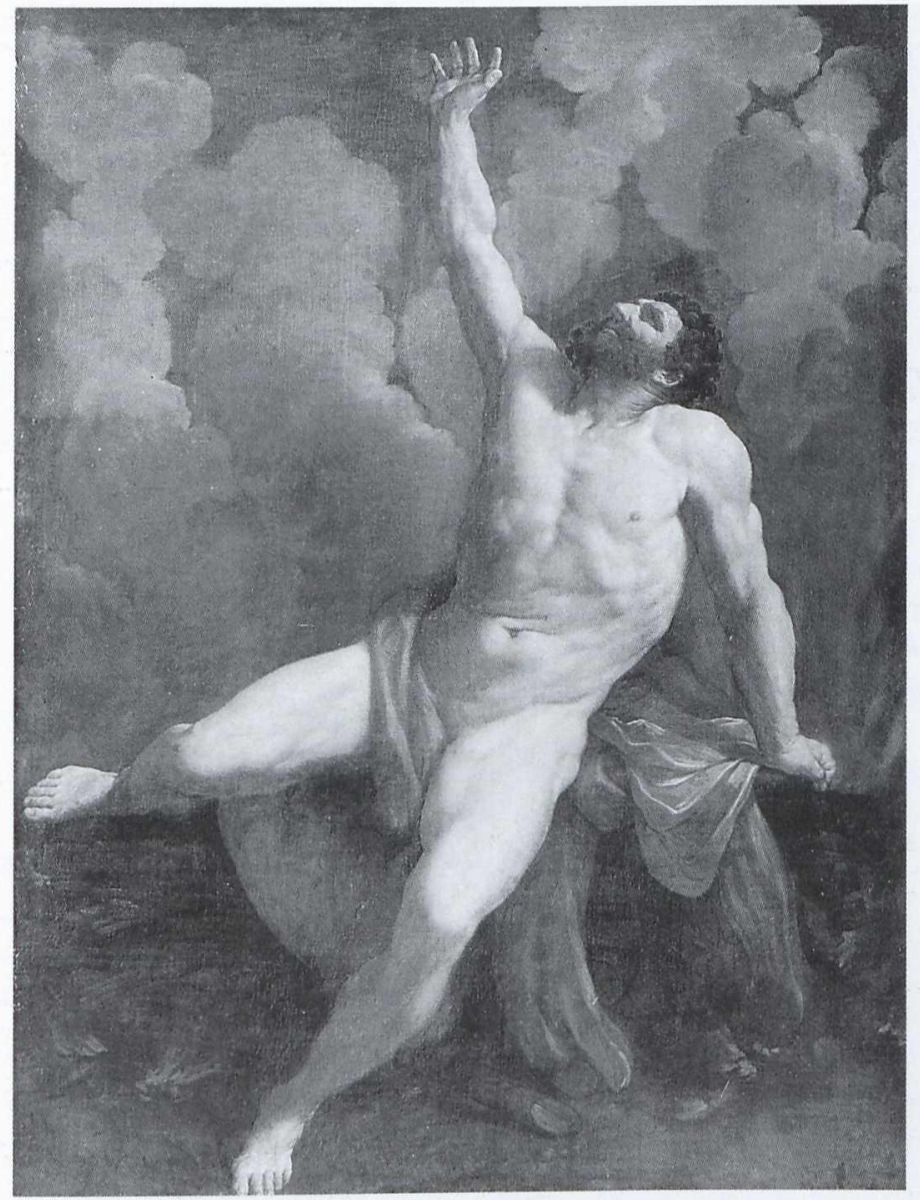

14) Guido Reni, «Herkules auf dem Scheiterhaufen». Inv. 538, Louvre, Paris.

London, National Gallery) liegt ein Beispiel vor, bei dem der Künstler seine Vorgabe - das Relief eines Adonis-Sarkophags (Abb. 4: Mantua, Palazzo Ducale) ${ }^{36}$ — nicht (wie in den zuvor genannten Fällen) christlich uminterpretierte, sondern zur Gestaltung einer analogen antiken Szene nutzte.

In der Reihe der vier Gonzaga-Bilder nun ist ein solcher Rückgriff auf Antiken vielleicht am offenkundigsten bei "Nessus und Deinaeira" [Abb. 5] zu beobachten, scheint Reni sich bei der Beschreibung des Kentauernkörpers doch an der berühmten Borghese-Skulptur ${ }^{37}$ [Abb. 6] orientiert zu haben, deren Niederschlag vielleicht sogar noch unmittelbarer in einem vorbereitenden Studienblatt [Abb. 7: Melbourne,

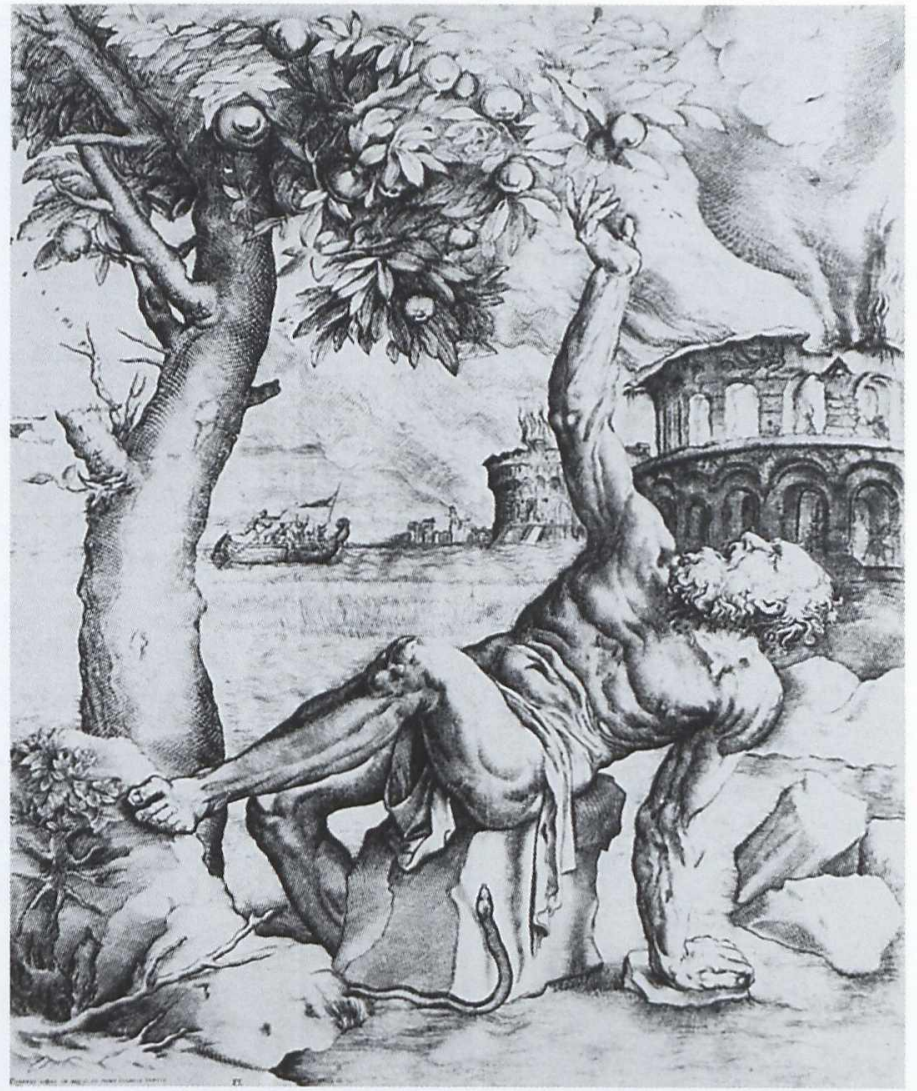

15) Giulio Sanuto: Stich nach Tizians "Tantalus".

National Gallery of Victoria] ${ }^{38}$ verfolgt werden kann: der seitlich nach hinten gewendete Kopf, der sich in der Rückwärtswendung straffende und zugleich in seiner plastischen Modellierung stärker artikulierende Leib sowie dessen deltaförmige Einmündung in den Pferdekörper legen ein beredtes Zeugnis von Renis Auseinandersetzung mit der antiken Vorlage ab.

Für "Herkules und Acheloos" [Abb. 8] hingegen konnte Arne Brenna 1955 nachweisen, daß Reni sich bei der Komposition der miteinander ringenden Streiter des Vorbildes einer hellenistischen Athletengruppe aus Bronze [Abb. 9: München, Glyptothek] bedient hatte ${ }^{39}$.

Komplizierter scheint der Fall bei dem "Hydra"-Bild [Abb. 10] zu liegen, da die von Brigitte Borchhardt-Birbaumer 1991 vorgeschlagenen, antiken Kampfdarstellungen [vgl. z.B. Abb. 


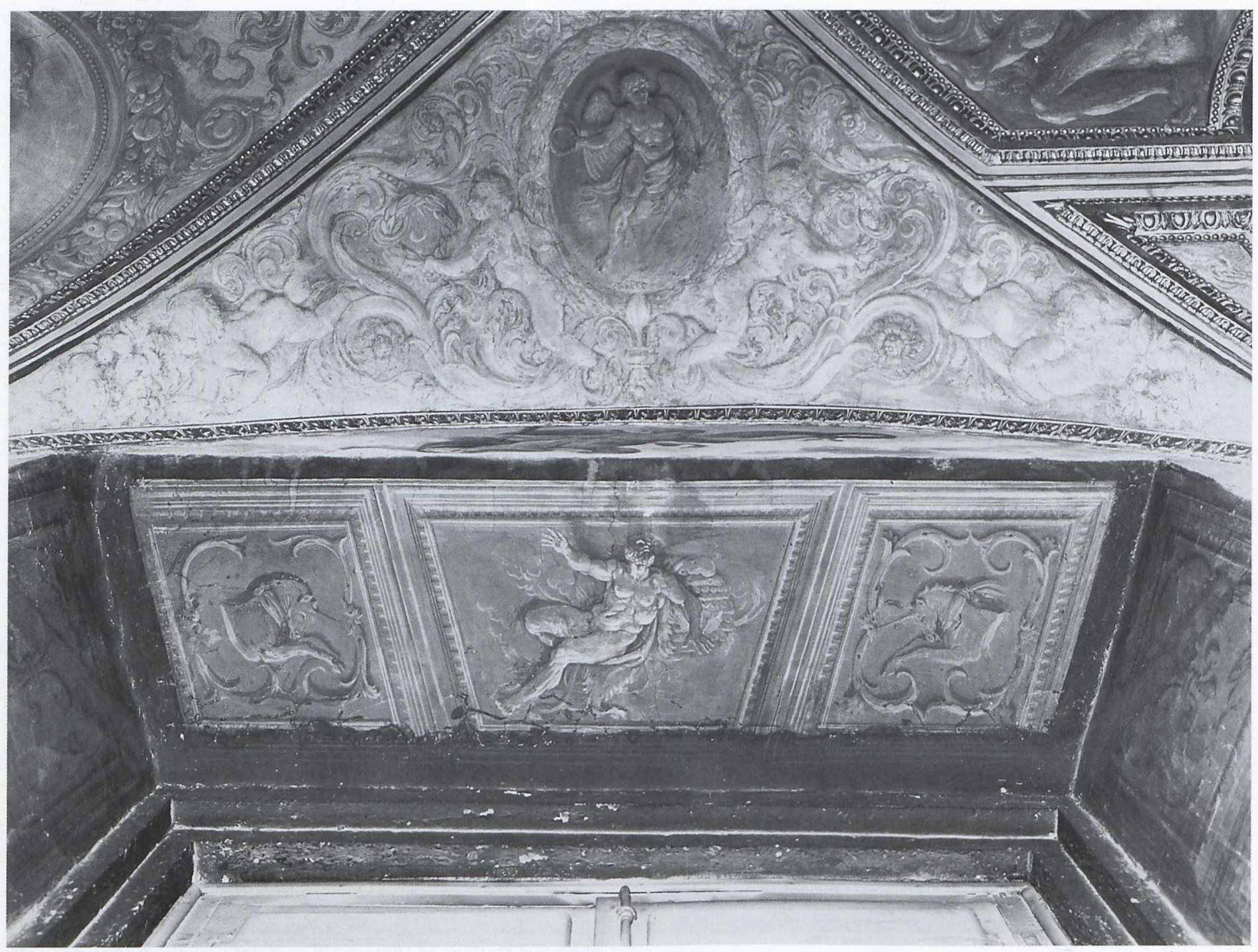

16) Annibale Carracci «Herkules»-Fresko im Camerino Farnese. Palazzo Farnese, Rom.

$11]^{40}$ über generische Parallelen (beidesmal sind zum Schlag ausholende Kämpfer dargestellt) hinaus keinerlei Verwandtschaft aufweisen ${ }^{41}$ : gerade das charakteristische Motiv des vor dem Kopf hinweggeführten und somit die untere Gesichtshälfte verdeckenden Armes bei gleichzeitiger Seitwärtsdrehung des mächtigen Leibes in der Hüfte unterscheidet Renis Komposition deutlich von den diesbezüglich vorge- schlagenen Vorbildern ${ }^{42}$. Eben diese markante Kombination von Bewegungen konnte Reni jedoch anhand einer antiken Skulptur studieren, die kurz vor 1623 aufgefunden worden zu sein scheint, und deren Entdeckung für Furore sorgte: die Statuengruppe von "Paetus und Arria", bekannter unter der Bezeichnung als "Gallier Ludovisi" (Rom, Museo Nazionale, jetzt im Palazzo Altemps ausgestellt) ${ }^{43}$. Wie ein Blick auf spä- 
tere Seicento-Stichwiedergaben der Skulptur zeigt, [Abb. $12]^{44}$ wurde die Gruppe gerne in einer Frontalansicht aufgenommen, aus der heraus die tatsächlich den bewaffneten Arm gegen die eigene Brust führende Geste des Galliers wie zu einem mächtigen Schlag ausholend erscheint - eine Gebärde, die diese Figur eben für Renis "Herkules" interessant machen konnte. Es ist dies vielleicht auch der Moment, an die oben bereits zitierte, bis jetzt rätselhaft gebliebene Depesche Barbazzis zu erinnern, der eben im Januar 1623 unmittelbar nach der wahrscheinlichen Auffindung des antiken "Galliers" in Rom ${ }^{45}$ — an seinen Herrn von dem "capricio" Renis berichten muß, der im letzten Augenblick die bereits ausgereifte Komposition eines Gemäldes wieder verworfen habe, um "tutta una figura" zu ändern. Während diese Meldung bislang unverständlich schien, da nicht erkennbar war, was den plötzlichen Sinneswandel Renis provoziert haben mochte 46 , könnten die Entdeckung des antiken "Galliers" zum Jahreswechsel 1622/23 und der Wunsch des Künstlers, seinen hydratötenden Herkules noch mit dessen mächtiger Geste zu versehen, eine plausible Erklärung für Renis brüsken Entschluß sein, "di mutar tutta una figura" 47.

Angesichts des Umstandes, daß Reni sich mithin für drei Gemälde des Gonzaga-Zyklus' bei antiken Skulpturen mit Inspirationen versorgt hätte, stellt sich die Frage umso dringender, ob auch schon das in einem Abstand von immerhin fast sechs Jahren zuerst fertiggestellte Bild des "Herkules auf dem Scheiterhaufen" [Abb. 14] solche Bezüge zur Skulptur des klassischen Altertums aufweise. Diese Frage wurde von seiten der Reni-Forschung bislang stets bejaht - obwohl kein konkretes Modell zur Verfügung stand, auf das man überzeugend hätte verweisen können.

Während die machtvollen Leiber des Torso Belvedere ${ }^{48}$ und des Laokoon ${ }^{49}$ - wenig offenkundig - als mögliche Vorbilder für die Gestalt des sich zum Firmament emporreckenden Heroen bemüht wurden, schienen indes Tizians "Tantalus"50 [Abb. 15], insbesondere jedoch der sterbende Herkules von der Hand Annibale Carraccis im Camerino Farnese $^{51}$ [Abb. 16] sehr viel besser dazu geeignet, Reni mit Anregungen zu versehen. Weist der Torso Belvedere - abgesehen von der gleichfalls wuchtigen Physiognomie - in seiner sonst ganz anders ausfallenden, da den Körper vornüber beugenden Haltung keinerlei Parallelen zu Renis Herkules auf, so gilt Entsprechendes für den Laokoon: auf den ersten Blick scheint sich hier zwar ein Zusammenspiel ähnlicher Gesten beobachten zu lassen (vgl. den je zurückgelegten Kopf sowie die in beiden Fällen gesenkten linken Arme, denen je ein erhobener rechter Arm antwortet), doch windet sich der Laokoon unter einer starken, seinen Brustkorb hervorstemmenden Spannung, während Renis Figur aus einer

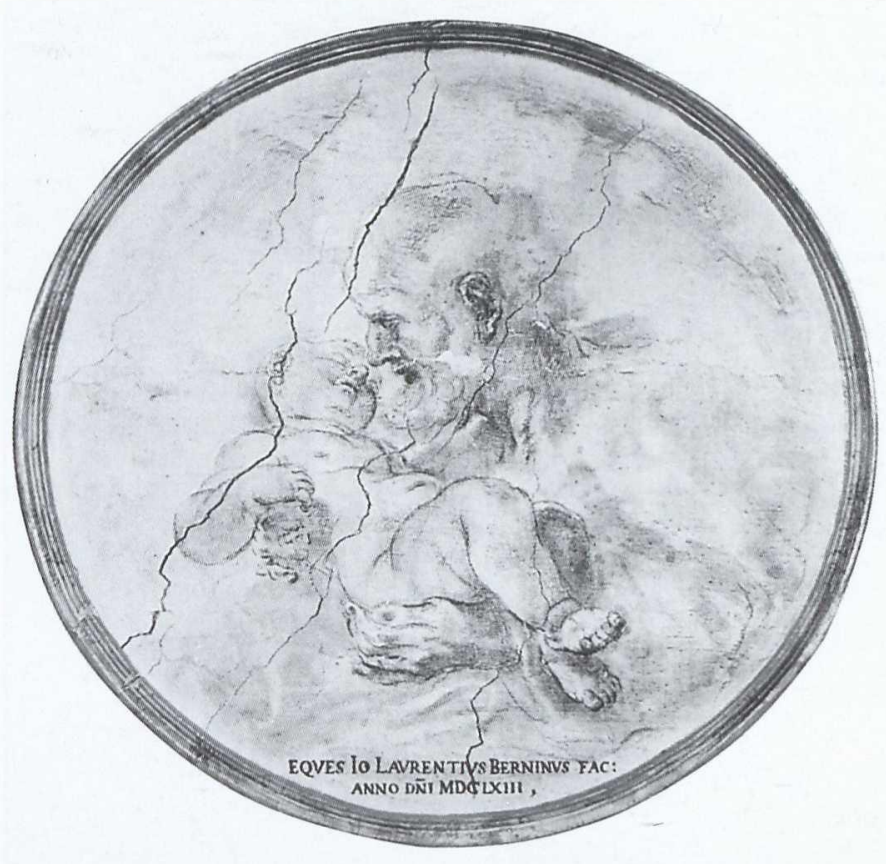

17) Gian Lorenzo Bernini, Zeichnung in der Hauskapelle des Palazzo Chigi, Ariccia.

lagernden Position heraus nach oben ausgreift. Eine diesbezüglich ähnliche, den Oberkörper bei erhobenem rechtem Arm auf der linken Hand aufruhende Haltung nimmt jedoch der Protagonist in Giulio Sanutos Nachstich von Tizians "Tantalus" ein, dem Annibale Carracci diese Pose entlehnt und auf seinen "Herkules auf dem Scheiterhaufen" im Camerino Farnese von 1597 angewendet zu haben scheint; gleichwohl wendet der sterbende Held hier seinen Kopf nach hinten zurück, während das Gewicht seines Körpers nicht mit der linken, offenbar frei gestikulierenden Hand abgefangen zu werden scheint.

Indem einzelne Motive bezüglich Körperhaltung und Gestik von Renis Herkules mithin über Tizian bzw. Annibale Carracci vermittelt worden sein könnten, weist der Protagonist des Gonzaga-Bildes jedoch darüber hinaus mit seinem erhobenen rechten und seinem gesenkten linken Arm, dem zurückgelegten Kopf, seiner Sitzhaltung sowie insbesondere dem gedrehten Rumpf und seiner auf Höhe des Bauchnabels verlaufenden Rechtswendung starke Parallelen zu einer antiken Skulptur auf, die möglicherweise auch 


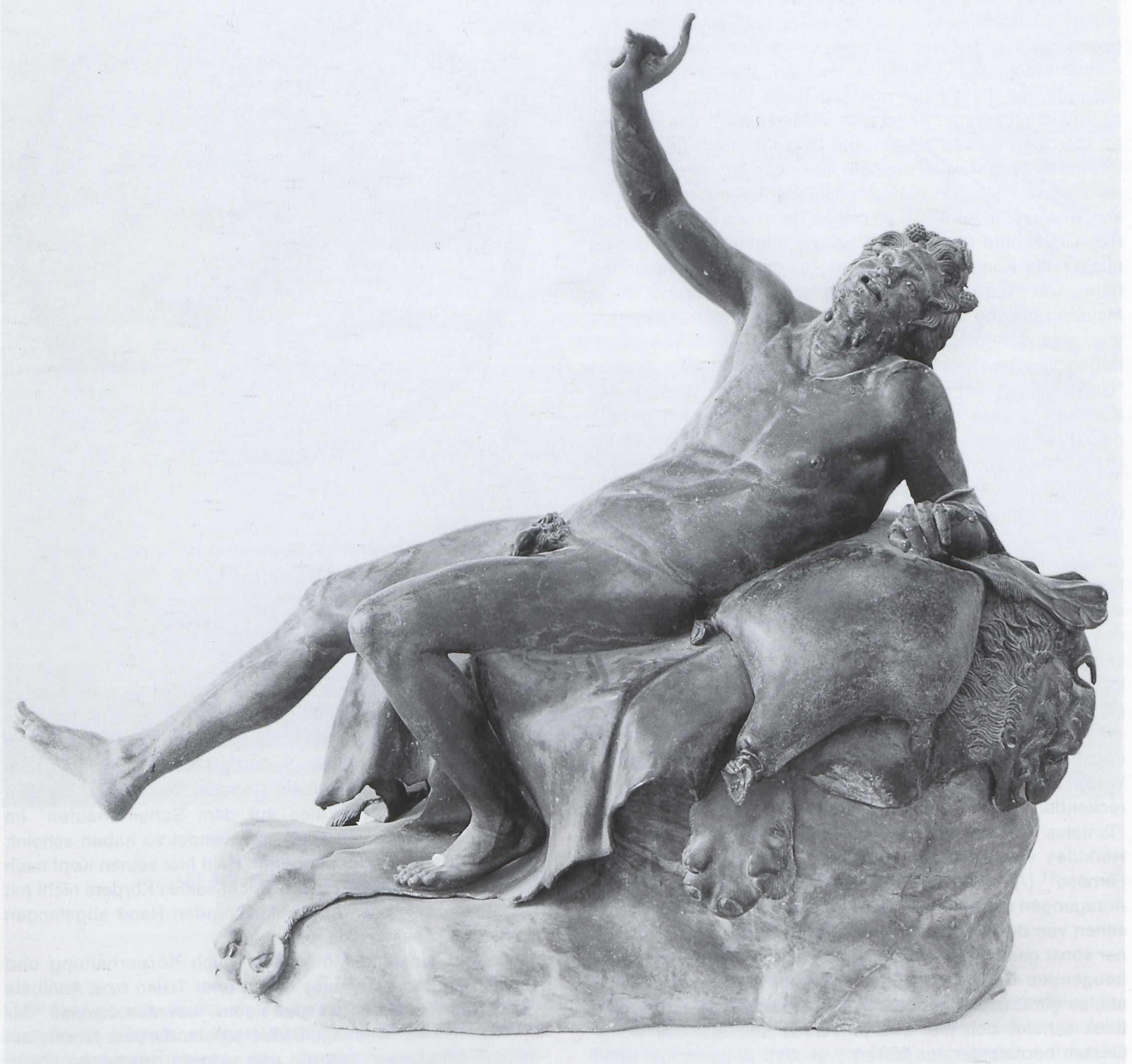

18) Antike Bronzeskulptur eines ein Schnippchen schlagendes Faunes. Museo Archeologico, Neapel. 


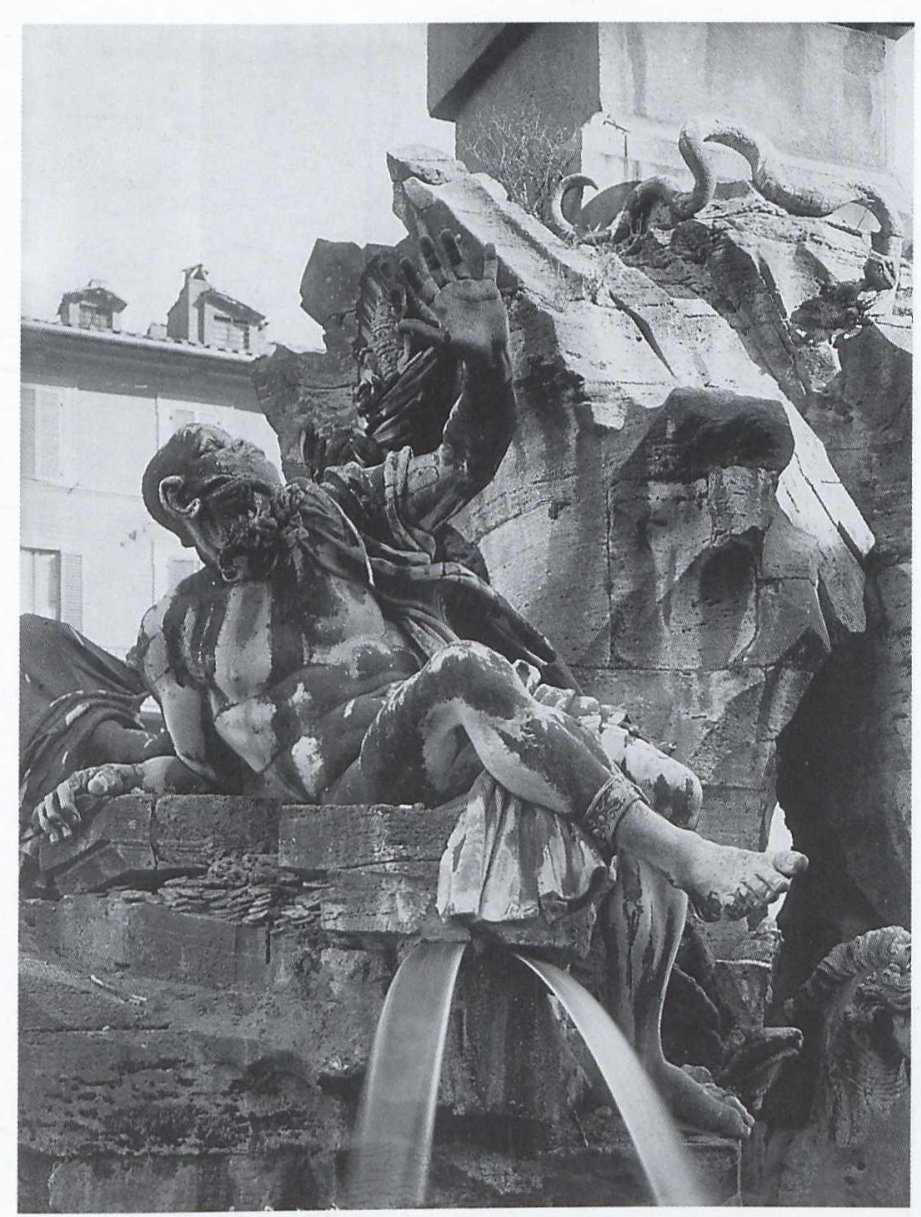

19) Gian Lorenzo Bernini, «Rio della Plata». Piazza Navona, Rom.

einem anderen, immer wieder mit Reni assoziierten Künstler bekannt gewesen zu sein scheint. Ursula Schlegel hat 1985 auf die Momente hingewiesen, in denen sich das Oeuvre Gian Lorenzo Berninis mit den Schöpfungen Guido Renis an den Schaltstellen gemeinsam verwendeter Motive - zufällig oder qua Rezeption - kreuzt; stellvertretend als nur ein Beispiel sei hier kurz auf eine in Rötel und Ölfarbe an der Wand der Hauskapelle des Palazzo Chigi in Ariccia ausgeführte und auf 1663 datierte Zeichnung Berninis verwiesen [Abb. 17], die eindeutig Bezüge zu Renis Kompositionen eines "Heiligen Joseph mit dem Christuskind" [vgl. z.B. Abb. 1] aufweist ${ }^{52}$.

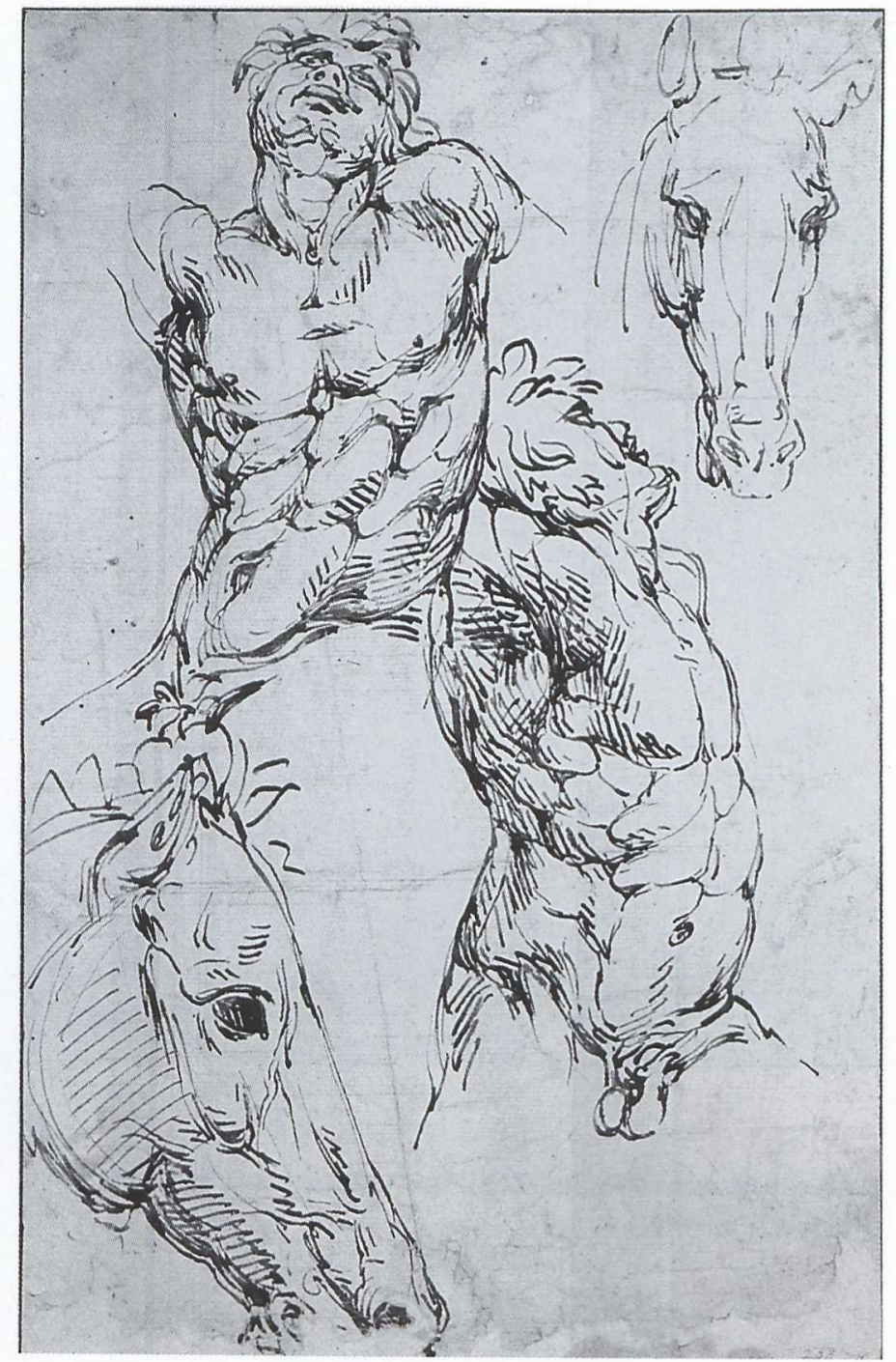

20) Tiburzio Passarotti, Zeichnung eines Faun-Torsos. Albertina, Wien.

Obgleich Bernini nun - wie ein Blick auf eine im Oktober 1665 Chantelou gezeigte ${ }^{53}$, bislang als Rezeptionsbeleg nicht erkannte Zeichnung [Abb. 13 $]^{54}$ lehrt - Renis "Herkules"Zyklus ganz oder zumindestens mit dem "Hydra"-Bild [Abb. 10] ausschnittweise kannte (das heute im Louvre verwahrte Blatt variiert unverkennbar die zum Schlag ausholende Gebärde von Renis Drachentöter zu einem an einer Schlinge 


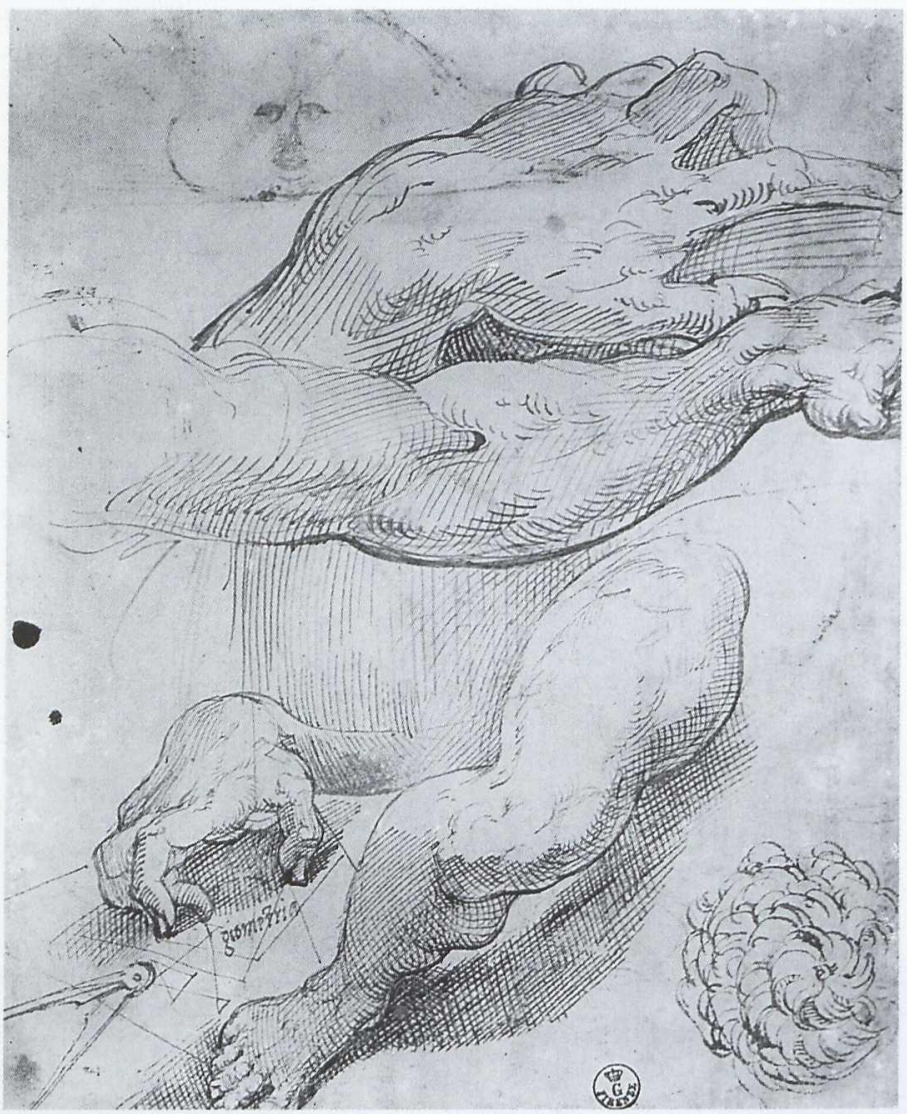

21) Bartolommeo Passarotti, Studienblatt. Inv. $12611 \mathrm{~F}$, Uffizien, Florenz.

zerrenden Krieger ${ }^{55}$ ), scheint der vorliegende Fall eher unter die Rubrik der parallelen Verwendungen und Rezeptionen einzuordnen sein, weist doch der hinter Renis Herkules stehende antike Typ eines ein Schnippchen schlagenden Faunes [künstlerisch wohl am prachtvollsten vertreten mit dem Bronze-Exemplar aus Herkulaneum im Neapolitaner Museo Archeologico: Abb. 18 ${ }^{56}$ in Körperhaltung und Gestik zugleich eine auffällige Verwandschaft zum Rio della Plata an Berninis "Vierströmebrunnen" an der Piazza Navona in Rom auf $\left[\right.$ Abb. 19] ${ }^{57}$.

Während Bernini die Ponderierung und Lagerung der Figur an einem vollständiger erhaltenen Exemplar ${ }^{58}$, eventuell auch anhand einer der die Verbreitung der Figur bezeugenden antiken Münzen ${ }^{59}$ studiert haben könnte, wurde Reni die Figur

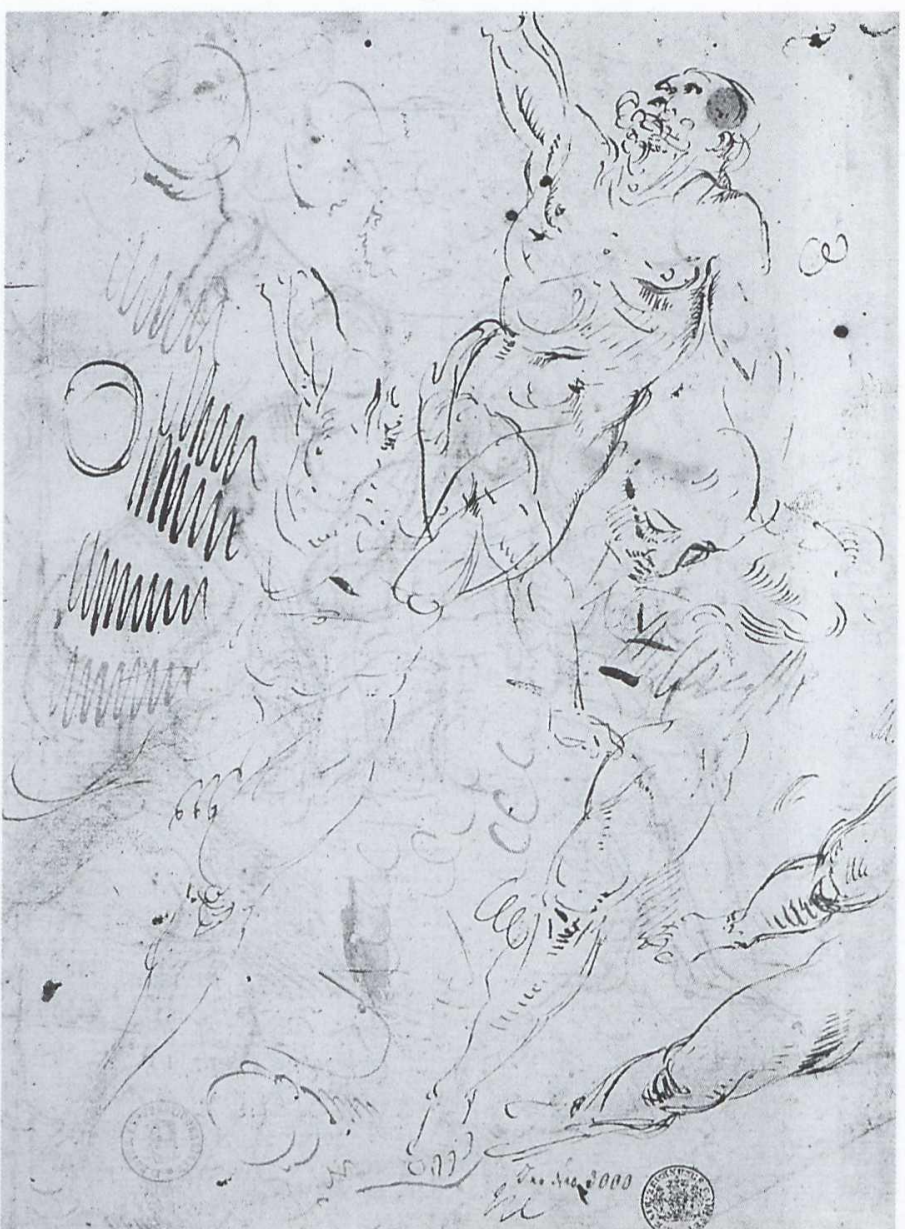

22) Guido Reni, Studienblatt. Inv. 3000, Graphische Sammlung, München.

sicherlich in einer anderen Form vermittelt: eine in der Albertina zu Wien aufbewahrte, früher irrtümlich Michelangelo ${ }^{60}$, dann wohl korrekt Tiburzio Passarotti (ca. 15551612) zugeschriebene Zeichnung [Abb. 20] ${ }^{61}$ nimmt den gleichen Typ Faun tatsächlich in einer torsohaften Form auf, die dem Zustand der Auffindung der meisten, uns heute bekannten Faune dieses Typs entspricht ${ }^{62}$. Daß Reni bei der Ausführung des "Herkules auf dem Scheiterhaufen" Zeichnungen der beiden, damals bereits verstorbenen Passarotti in Bologna zugänglich gewesen sein müssen, hat Catherine Johnston bereits 1969 nachweisen können, als sie das von 


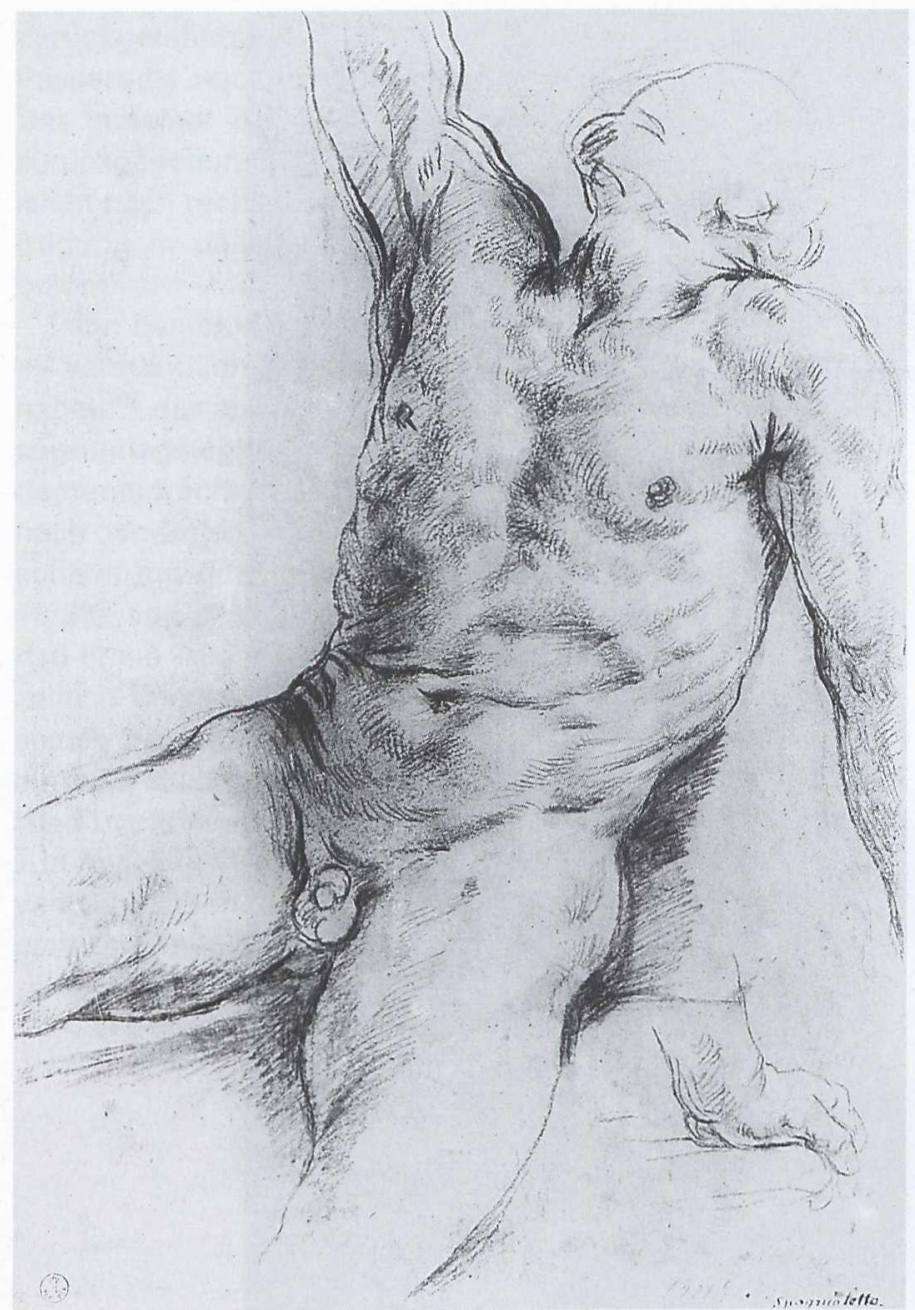

23) Guido Reni, Studienblatt zum "Herkules auf dem Scheiterhaufen". Inv. 10113 S, Uffizien, Florenz.

Reni auf einer Zeichnung der Sammlung Fachsenfeld festgehaltene rechte Bein des sterbenden Herkules auf ein Studienblatt von der Hand Bartolommeo Passarottis [Abb. 21] zurückführen konnte ${ }^{63}$.

Von der Zeichnung Tiburzio Passarottis [Abb. 20] nun, ausgeführt möglicherweise nach einem Objekt aus seiner reichen und berühmten, von seinem Vater angelegten und durch inn erweiterten Antikensammlung, einem obligatorischen Besuchsziel prominenter Bologna-Reisender ${ }^{64}$, scheint Reni

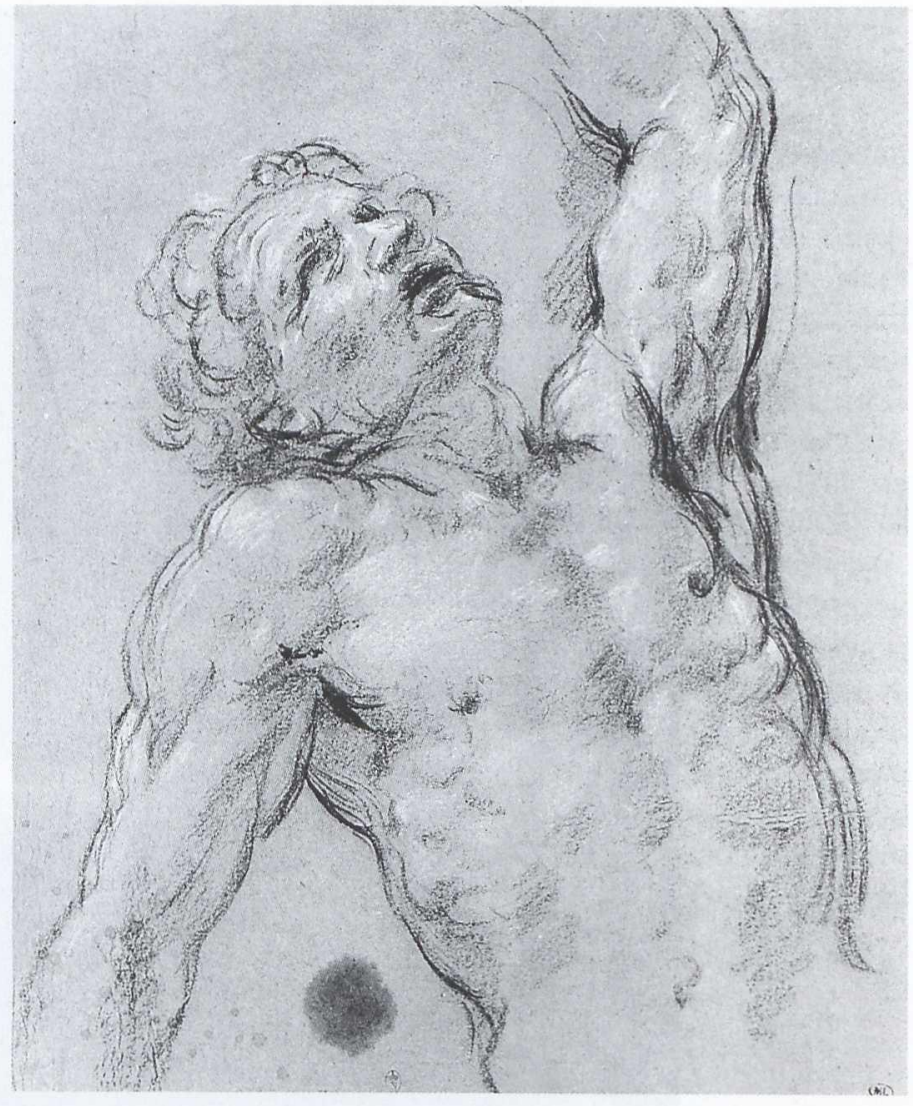

24) Guido Reni, Vorzeichnung für "Apoll schindet Marsyas". Inv. 8917, Louvre, Paris.

die Anregung zur Positionierung seines Herkules auf dem Scheiterhaufen empfangen zu haben: probeweise wendete er die dort gefundene Pose sodann in einer mit schnellen, flüssigen Strichen gearbeiteten Skizze [Abb. 22 $]^{65}$ auf seinen Protagonisten an (vgl. den auf beiden Blättern fast genau gleich gegebenen Körperausschnitt, der Arm- und Beinstümpfe nur andeutet, während Rumpf und Kopf ganz ausgeführt werden; unten rechts findet sich auch bereits schon das Bein der Florentiner Passarotti-Zeichnung - Abb. 21 notiert), ehe er schließlich die entsprechende Stellung von seinem Modell einnehmen ließ, das er in der Uffizien-Zeichnung [Abb. 23] festhielt: der erhobene rechte sowie der gesenkte linke Arm; der zurückgelegte, die hochgezogene linke Schulter mit dem Nacken berührende Kopf sowie die leicht 


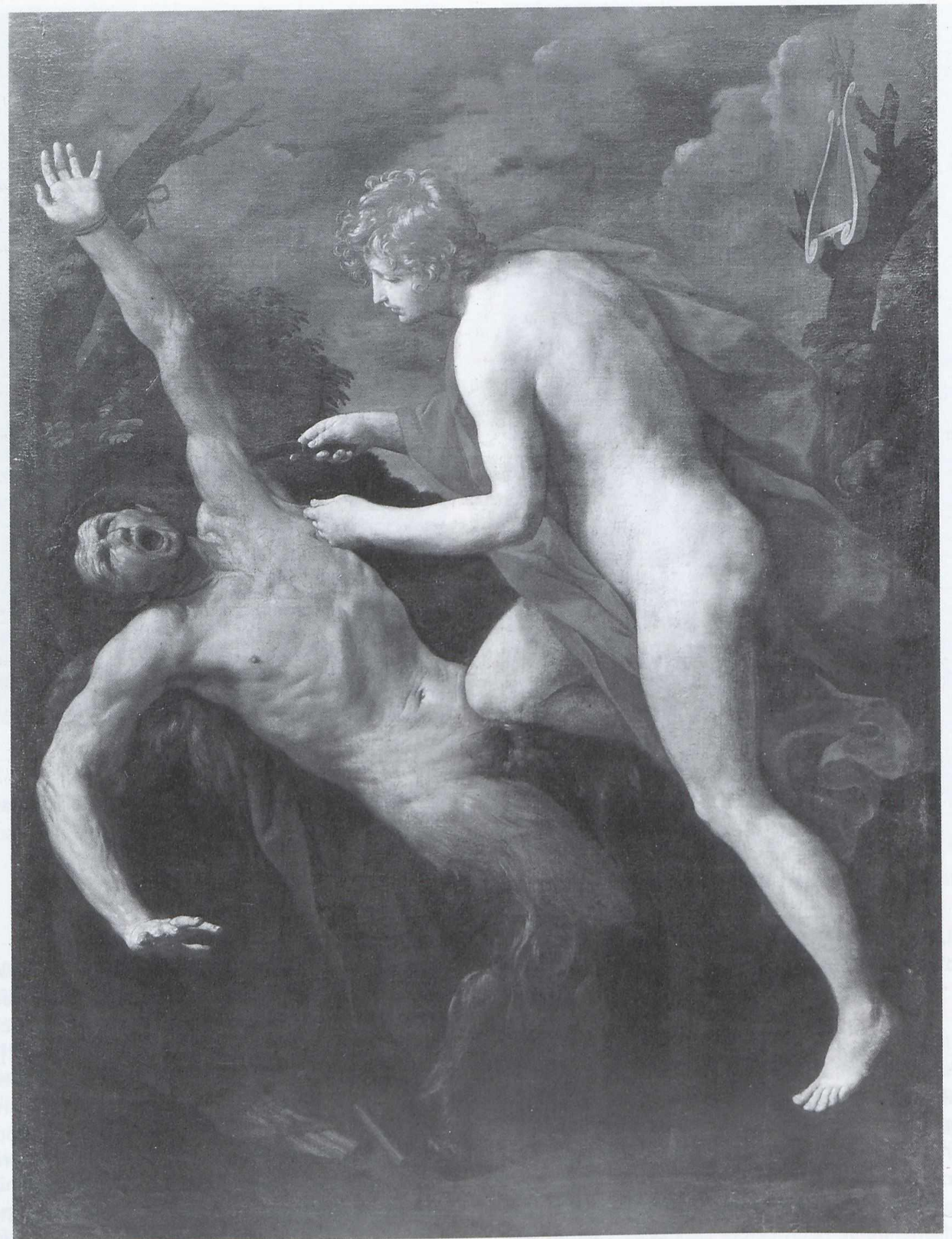

25) Guido Reni, «Apoll schindet Marsyas». Alte Pinakothek, München. 
zurückgelehnte Sitzhaltung lassen in der Faun-Zeichnung Passarottis noch immer Renis Inspirationsquelle erkennen. Das in seiner Zeichnung noch gegenüber dem Vorbild eher zurückgenommene Motiv des auf der Höhe des Bauchnabels leicht nach rechts gewendeten Rumpfes wurde bei der Übertragung in das Gemälde [Abb. 14] sogar wieder stärker betont.

Ihn besonders gelungen anmutende Posen scheint Reni - verständlicherweise - mehr als einmal verwendet zu haben: ${ }^{66}$ das antike Vorbild der dem "Acheloos"-Bild [Abb. 8] zugrundegelegten, hellenistischen Bronzeathleten nutzte er dementsprechend auch für die Figur der sich im Wettlauf nach den Goldäpfeln bückenden Atalanta ${ }^{67}$. Ein paralleler Fall scheint mit dem Fund des Faunes gegeben zu sein (Abb. $18 / 20$ ), von dessen Pose er so angetan gewesen sein muß, daß er sie - ebenso wie bei "Acheloos" und "Atalanta" — in zeitlich unmittelbarer Nachbarschaft erneut der Konzeption seines Gemäldes "Apoll schindet Marsyas" zugrundelegte: in einer Zeichnung [Abb. 24: Paris, Louvre] ${ }^{68}$ nahm er zunächst wieder die zuvor erfolgreich umgesetzte Kombination aus zurückgelegtem Kopf, Drehung des Körpers und Gegenspiel von erhobenen und gesenkten Arm auf, die er für die letztendliche (möglicherweise erst rund acht Jahre später erfolg-

Eine erste knappe Präsentation der hier vorgelegten Ergebnisse erfolgte im Sommer 1998 während des Fourth Meeting of the International Society for the Classical Tradition in Tübingen; in ausführlicherer Form wurden die folgenden Darlegungen sodann anläßlich eines Vortrags zur Diskussion gestellt, der im Juni 2000 am Kunstgeschichtlichen Institut der Universität Marburg auf freundliche Einladung von Ingo Herklotz gehalten werden konnte. Ihm sowie Wolfgang Haase (Boston) sei für die damit je gegebene Möglichkeit gedankt, die Überlegungen gemeinsam mit den Zuhörern kritisch zu erörtern. te) Ausführung [München, Bayerische Staatsgemäldesammlungen: Abb. 25] ${ }^{69}$ dann jedoch noch erheblich dramatisierte.

Angesichts der an Renis "Herkules"-Zyklus angestellten Beobachtungen ist abschließend zu fragen, ob dieser, die Bilderfolge über das verbindende Element der HerkulesThematik hinaus verklammernde Rekurs auf die Antike nicht zum einen von dem Wunsch des Künstlers bestimmt war, den an ihn ergangenen und von ihm nachweislich als anspruchsvoll empfundenen Auftrag mit Hilfe des "beneficio delle statue" zu erfüllen; zum anderen kam er damit sicherlich dem raffinierten Geschmack des hochkultivierten Ferdinando Gonzaga entgegen, den er 1622 - sicherlich nicht zufällig mit der gemalten Paraphrase eines antiken Sarkophagreliefs, der "Toilette der Venus" [s.o.; Abb. 3 und 4], belieferte. Schließlich aber ist diese Praxis auch im Lichte jener Antwort zu sehen, die Reni denjenigen gab, die sein malerisches Genie als ein Geschenk des Himmels zu verstehen versuchten: “(...) questi doni s' aquistano a forza di fatiche, queste idee che vogliono $\mathrm{mi}$ siano rivelate, le discoprono le belle teste delle statue antiche, studiandoci sopra, come per ott'anni continui ho fatto, disegnandole per ogni verso e per ogni veduta, fortificato nella loro stupenda armonia (...)."70

Vgl. die Erstpublikation dieser Dokumente durch Willelmo Braghirolli, "Guido Reni e Ferdinando Gonzaga", in: Rivista storica mantovana 1, Fas. 1-2, 1885, p. 88-99. Erste Korrekturen und Ergänzungen unternahm bereits Pamela Askew, "Ferdinando Gonzaga's Patronage of the Pictorial Arts: The Villa Favorita”, in: Art Bulletin, 60, 1978, p. 274-295, hier p. 283, Anm. 94; eine vollständige und korrigierende Neuedition wurde schließlich von Stephen Pepper und Raffaella Morselli in ihrem Artikel "Guido Reni's Hercules-series: new considerations and conclusions", in: Studi di Storia dell'arte, 4, 1993, p. 129-147 vorgelegt. 
2 Vgl. u.a. Askew (Anm. 1), p. 283, wo die von Braghirolli (Anm. 1), p. 100 mitgeteilte Datierung dieses Briefes auf den 22. Juni 1617 auf den 23. Juni korrigiert wird.

3 Braghirolli (Anm. 1), p. 90 und p. 100, Doc. I; zu den diesbezüglichen, widersprüchlichen Quellen vgl. Askew (Anm. 1), p. $283 f$.

4 Vgl. die diesbezüglichen Dokumente bei A. Luzio, La Galleria dei Gonzaga venduta in Inghilterra nel 1627-28, Mailand 1913, p. 90. Catherine Johnston, "Quelques dessins de Guido Reni pour la suite d'Hercule", in: Revue de l'art, 3, 1969, p. 72-74, hat p. 74, Anm. 10 den Schluß daraus gezogen, daß die "Herkules"-Gemälde nie für die Villa Favorita bestimmt gewesen seien - wie Frances Van Keuren, "Guido Reni's 'Contest of Hercules and Achelous' and the 'Hercules' series", in: Source - Notes in the History of Art, 9, 1990, p. 5-13, jedoch p. 10 richtig bemerkt, könnte es ebensogut sein, daß die vier Gemälde erst nach einem ersten Verbleib in der Villa Favorita anschließend in besagten Korridor umgehängt wurden.

5 Zur Provenienz und Verkaufsgeschichte der Bilder sowie dem diesbezüglichen Forschungsstand vgl. ausführlich Stéphane Loire, École italienne, XVIle siècle - 1. Bologne, Paris 1996, p. 308 - 323.

6 Braghirolli (Anm. 1), p. 92 und p. 102, Doc. V, Askew (Anm. 1), p. 284 sowie Pepper/Morselli (Anm. 1), p. 137, Doc. IV. Vgl. dort auch eine sehr hypothetische, eben auf der Lichtsituation in den einzelnen Gemälden basierende Rekonstruktion von deren Hängung. Askew (Anm. 1), p. 284 weist ferner daraufhin, Renis Formulierung, er bedürfe "di novo" der den Bildern zugrunde zu legenden Formate, impliziere, daß der Maler zuvor schon einmal selbst Maß genommen oder aber diese mitgeteilt bekommen habe. Tatsächlich könnte sich "di novo" jedoch auch einfach auf den Umstand beziehen, daß Reni eine Bestätigung der dem bereits zwei Jahre zuvor vollendeten "Herkules auf dem Scheiterhaufen" zugrundegelegten Maße erbat.

7 Vgl. Anm. 4.

8 Veronika Birke in: Guido Reni und Europa - Ruhm und Nachruhm, Ausst.Kat. hrsg. von Sybille Ebert-Schifferer, Andrea Emiliani und Erich Schleier, Frankfurt/M. 1988, p. 344 sowie in Guido Reni und der Reproduktionsstich, Ausst.Kat. hrsg. von Veronika Birke, Wien 1988, p. 72 f., No. 31.

9 Vgl. z.B. die Gemäldedekorationen Lucas Cranachs im Schlafgemach des Herzogs von Sachsen in Wittenberg, die - dem "Dialogus" des Andreas Meinhard zufolge - u.a. Herkules-Szenen umfasst haben sollen; vgl. dazu Franz Matsche, "Lucas Cranachs mythologische Darstellungen", in: Lucas Cranach. Ein MalerUnternehmer aus Franken, hrsg. von Claus Grimm u.a., Regensburg 1994, p. 78-88; Edgar C. Reinke, The Dialogus of Andreas Meinhardi (1508). An Utopian Description of Wittenberg and its University, Ann Arbor 1976 (mein herzlicher Dank geht an Susanne Kress [Giessen], die mich freundlicherweise auf diese Literatur verwiesen hat).

10 Vgl. dazu auch Van Keuren (Anm. 4), p. 9.

11 Zur christologischen Deutung vgl. erstmals Veronika Birke, Guido Reni - Zeichnungen, Ausst. Kat. hrsg. von Veronika Birke, Wien, Albertina 1981, p. 118, No. 81, wo Herkules als "'propugnator' Christi" interpretiert wird; zu deren Aufnahme vgl. z.B. sowohl Van Keuren (Anm. 4), p. 10f. und Stéphane Loire, "Guido Reni dopo la mostra di Bologna: qualche aggiunta", in: Accdemia Clementina. Atti e Memorie, No. 25, 1990, p. 9-30, hier p. 14-20, als auch Pepper/Morselli (Anm. 1), p. 132, wo die entsprechenden Überlegungen Birkes entweder moralisch (Van Keuren/Loire) oder aber politisch (Pepper-Morselli) zugespitzt werden. Askew (Anm. 1), p. 284 und 295 interpretiert die gewählte Herkules-Thematik der vier Bilder noch im Hinblick auf eine Herrscher-lkonographie von Macht, Tugend und Weisheit. Zu Herkules als Exemplum Virtutis sowohl der heidnischen wie auch der christlichen Kultur vgl. generell G. Karl Galinsky, The Herakles Theme - The
Adaptions of the Hero in Literature from Homer to the Twentieth Century, Oxford 1972, insbes. Kapitel 9 sowie Rainer Vollkommer, "Herakles - Die Geburt eines Vorbildes und sein Fortbestehen bis in die Neuzeit”, in: Idea (Jahrbuch der Hamburger Kunsthalle), VI, 1987, p. 7-29. Zur Parallelisierung von Herkules mit Christus vgl. speziell Friedrich Pfister, "Herakles und Christus", in: Archiv für Religionswissenschaft, Vol. 34 , 1937, p. 42-60 sowie Marcel Simon, Hercule et le christianisme, Paris 1955, insbes. Kapitel 2, 3 und 5.

12 Vgl. Birke 1988 (Anm. 8), p. 342, zuerst kritisiert von Van Keuren (Anm. 4), der p. 9 (unter Verweis auf die Erzählchronologie sowie die Reihenfolge von Naglers Auflistung der RousseletNachstiche) eine Abfolge von "Hydra" - "Acheloos" - Nessus" "Scheiterhaufen" postuliert, wie sie auch von Loire 1990 (Anm.11), p. 18 (wiederholt in Loire 1996 [Anm. 5], p. 319) und Ladislav Daniel "Reniana", in: Bulletin of the National Gallery in Prague, II, 1992, p. 42 -57 , hier p. 42 vorgeschlagen wird. Der Anordnung Daniels, p. 49 folgend, der "Hydra" und "Scheiterhaufen" als von rechts beleuchtete Bilder nebeneinander an einer Wand den von links erhellten Szenen mit "Acheloos" und "Nessus" gegenüberhängt, rekonstruieren Pepper/Morselli (Anm. 1), p. 131 aufgrund der Beleuchtungssituation die Sequenz von "Acheloos" _ "Nessus" _ "Hydra" "Scheiterhaufen"; Loire 1996 (Anm. 5), p. 319 zufolge hätten die zweifigurigen Szenen etwas tiefer gehangen.

13 Diese Abfolge wurde von Gian Carlo Cavalli in seinem gemeinsam mit Cesare Gnudi verfassten Buch Guido Reni, Florenz 1955, p. 71 aufgrund einer Erwähnung der noch auszuführenden Bildthemen in einem Brief Barbazzis vom 9. Januar 1619 (Braghirolli [Anm. 1], p. 92; Pepper/Morselli [Anm. 1], p. 137, Doc. IV) erschlossen - wie bereits Askew (Anm. 1), p. 284, Anm. 112 und Richard Spear, "Re-viewing the 'Divine Guido'”, in: Burlington Magazine, CXXXI, 1989, p. 371 richtig anmerkten, könnte es sich hierbei um eine rein zufällig anordnende Auflistung handeln.

14 Siehe Anm. 1.

15 Braghirolli (Anm. 1), p. 104, Doc. IX; Pepper/Morselli (Anm. 1), p. 138 , Doc. $X$

16 Pepper/Morselli (Anm. 1), p. 139, Doc. XI.

17 Pepper/Morselli (Anm. 1), p. 139, Doc. XIII.

$18 \mathrm{Zu}$ den Gründen vgl. Pepper/Morselli (Anm. 1), p. 132, wo plausibel gemacht wird, daß sich dieser Teil der Korrespondenz nur auf ein Bild des "Herkules"-Zyklus' beziehen kann.

19 Vgl. z.B. Pepper/Morselli (Anm. 1), p. 130 sowie Loire 1996 (Anm. 5), p. 316

20 Vgl. Braghirolli (Anm. 1), p. 95

21 Der Abschluß der "Herkules"-Serie wird üblicherweise - vgl. z.B. Pepper/Morselli (Anm. 1), p. 130 sowie Loire 1996 (Anm. 5), p. 316 - auf spätestens November 1622 veranschlagt, da Barbazzi die Gemälde in einem auf den 16.11.1622 datierten, von den Gehaltsvorstellungen Renis berichtenden Brief (vgl. Braghirolli, p. 95) erwähnt: die dort benutzte Formulierung "li quadri che egli già fece a S.A. delle Forze d'Hercole" läßt jedoch noch keinen zwingenden Rückschluß auf eine Vollendung des gesamten Zyklus zu diesem Zeitpunkt zu, da die "Herkules"-Bilder lediglich aufgrund der mit ihnen verbundenen, vorab getroffenen Preisvereinbarungen als Vergleichsfaktor herangezogen werden. Dies wird besonders deutlich, wenn es sodann im folgenden Satz bezüglich der zu verhandelnden "Venus" und "Paris"-Gemälde heißt: "ma che questi che fabrica, e dei quali si tratta, non si è mai stabilito prezzo alcuno; et perchè sono molto differenti da quelli" [i.e. den "Herkules"-Bildern], d.h. die für den "Herkules"-Zyklus offenbar zuvor ausgehandelte Preispolitik kann hier nicht einfach übernommen werden, da die in Rede stehenden Bilder größere Formate und eine höhere Figurenanzahl aufweisen. 
22 Otto Kurz, "Guido Reni", in: Jahrbuch der Kunsthistorischen Sammlungen in Wien, N.F., Wien 1937, p. 205.

23 Birke 1981 (Anm. 11), p. 118

24 Vgl. Loire 1996 (Anm. 5), der p. 320 darauf hinweist, daß Malvasia in seinen von Marzocchi 1980 herausgegebenen biographischen Reni-Notizen sogar den Namen des entsprechenden Modells - "Bartolomeo detto Belcolare" - angibt; gleiches gilt für das Modell des Nessus, den Malvasia als "Giacomazzo Gasparini detto Giacomazzo" benennt: vgl. Lea Marzocchi, Le carte di Carlo Cesare Malvasia. Le "Vite" di Guido Reni e di Simone Cantarini dal manoscritto B. 16-17 della Biblioteca Comunale dell'Archiginnasio di Bologna, Bologna 1980, p. 31, Anm. 4 (für Bartolomeo Belcolare) und p. 30, Anm. 8 (für Giacomazzo Gasparini).

25 Loire (Anm. 5), p. 320.

26 Vgl. hierzu auch Birke 1988 (Anm. 8), p. 342.

27 Carlo Cesare Malvasia, Felsina Pittrice, hrsg. von Giampiero Zanotti, Bologna 1841, Vol. II, p. 54.

28 Malvasia, Felsina Pittrice (Anm. 27), Vol. II, p. 22; eine dort folgende (hinsichtlich der durch die "stupenda armonia" der Antiken gewonnene "fortificazzione") Passage ähnlich auch bei Giovan Pietro Bellori, Le vite de' pittori, scultori e architetti moderni, hrsg. von Evelina Borea, Turin 1976, p. 529 (siehe letzte Anm.).

29 Malvasia, Felsina Pittrice (Anm. 27), Vol. II, p. 57.

30 Bellori (Anm. 29), p. 529 und Giovanni Battista Passeri, Die Künstlerbiographien, hrsg. von Jacob Hess, Leipzig/Wien 1934, p. 81.

31 Vgl. Stephen Pepper, Guido Reni, Novara 1988, p. 296, No. 177 , dort datiert auf ca. 1638/40.

$32 \mathrm{Zu}$ dem Vergleich siehe Brigitte Birbaumer, "Verwandlungen der Motive antiker Kunst in den Werken Guido Renis", in: Kunsthistoriker, VII, 1990 , p. $34-42$, hier p. 40 sowie Brigitte Borchhardt-Birbaumer, "'Freizügigkeit und Mässigung'- Zur Antikenrezeption in den Werken Guido Renis", in: Wiener Jahrbuch für Kunstgeschichte, 44, 1991, p. 131-158, hier p. 154, No. 52. Zu der antiken Skulptur vgl. Nicholas Penny/Francis Haskell, Taste and the Antique, New Haven/London 1981, p. 307, No. 77 sowie Katrin Kalveram, Die Antikensammlung des Kardinals Scipione Borghese, Worms 1995, p. 17f., No. 105 - die Statue wurde bereits 1594 in einem Stich als der Sammlung Carlo Muti zugehörig festgehalten.

33 Vgl. Pepper 1988 (Anm. 31), p. 221f., No. 19: datiert auf $1605 / 6$.

34 Vgl. zu dieser Antike Penny/Haskell (Anm. 32), p. 212, No. 38 - Reni stand eventuell ein anderer Vertreter dieses Typs zur Verfügung, ist die vorliegende Skulptur doch erst ab 1638 in der Villa Borghese dokumentiert. Birbaumer 1990 (Anm. 32), p. 40 und Borchhardt-Birbaumer 1991 (Anm. 32), p. 142, No. 5 schlägt den Pothos des Skopas, Richard Spear, The "Divine" Guido - Religion, sex, money and art in the world of Guido Reni, New Haven/London 1997 , p. 284 hingegen den "Marble Faun" in den Kapitolinischen Museen (Penny/Haskell [Anm. 32], p. 209f., No. 36) als mögliches Modell vor.

35 Vgl. Pepper 1988 (Anm. 31), p. 248, No. 72.

36 Vgl. dazu Birbaumer 1990 (Anm. 32), p. 40 sowie BorchhardtBirbaumer 1991 (Anm. 32), p. 148, No. 24; zu dem Sarkophag vgl. Phyllis Pray-Bober/Ruth Rubinstein, Renaissance artists \& antique sculpture: a handbook of sources, London 1986, p. 64, No. 21.

37 Zu dieser Skulptur vgl. Penny/Haskell (Anm. 32), p. 179f., No. 21 sowie Kalveram (Anm. 32), p. 239f., No. 145; die Skulptur ist vor 1608 durch von Rubens angefertigte Zeichnungen dokumentiert. Zu seiner Vorbildfunktion für das Reni-Gemälde vgl. auch EbertSchifferer, in: Frankfurt 1988 (Anm. 8), p. 126 sowie BorchhardtBirbaumer 1991 (Anm. 32), p. 138 und 148, No. 23. Alexander
Dückers, Guido Reni - Beiträge zur Interpretation seiner Tafelmalerei, Laurensberg (Aachen) 1967, p. 33 schlägt als antikes Vorbild erstaunlicherweise den "Jungen Kentauren" aus den Kapitolinischen Museen zu Rom vor - dieser wurde jedoch nicht nur erst 1736 gefunden, sondern er teilt sich mit Renis "Nessus" auch sehr viel weniger Gemeinsamkeiten als der Borghese-Kentaur.

$38 \mathrm{Zu}$ diesem Studienblatt vgl. Veronika Birke in: Frankfurt 1988 (Anm. 8), p. 350, No. B 41.

39 Arne Brenna, "Guido Reni's 'Heracles and Achelous' and its Hellenistic Prototype", in: Burlington Magazine, XCVII, 1955, p. 151-152.

40 Hier abgebildet das Kentauromachie-Relief zweier zueinandermontierter Sarkophagschmalseiten (Vatikan, Sala delle Muse); zu diesen und zu deren Rezeption durch den Raffael-Umkreis vgl. Carl Robert, Die antiken Sarkophagreliefs, Vol. III, 1: Einzelmythen, Berlin 1887 , p. 151-155, No. 132. Zu den antiken Varianten der HydraIkonographie vgl. generell Peter F. B. Jongste, The Twelve Labours of Hercules on Roman Sarcophagi, Rom 1992, p. $16 f$.

41 Vgl. Dückers (Anm. 37), p. 33, der gleichfalls einen Sarkophag in den Giardini Boboli in Florenz als Quelle vorschlägt sowie Borchhardt-Birbaumer 1991 (Anm. 32), p. 146, No. 22. Zu einer grundsätzlichen, berechtigten Kritik an dem Verfahren Birbaumers vgl. Spear 1997 (Anm. 34), p. 387, Anm. 46.

42 Dückers (Anm. 37), p. 33 unternimmt daher auch erst gar keinen Versuch, für diese charakteristische Pose eine antike Quelle zu finden, sondern verweist auf das eventuelle Vorbild von Dürers "Tod des Orpheus" (als Zeichnung und Kupferstich in der Hamburger Kunsthalle: vgl. Friedrich Winkler, Die Zeichnungen Albrecht Dürers, Vol. I, 1484-1502, Berlin 1936, p. 43f., No. 58; Walter L. Strauss, The Complete Drawings of Albrecht Dürer, Vol. 1: 1471-1499, New York 1974 , p. 220 , No. $1494 / 11$ sowie, für den Stich, Arthur M. Hind, Early Italian Engravings, Vol. I, London 1938, p. 257f., No. 17); die maßgebliche, dort zum Schlag ausholende Mänade kehrt gespiegelt, doch sonst fast identisch in Dürers Stich "Herkules am Scheidewege" wieder (The Illustrated Bartsch, Vol. 10, New York 1980, p. 64, No. 73 [86]). Ein jedoch auch schon inhaltlich näherliegendes Modell wäre mit Frans Floris' heute verlorener, nur in einem Nachstich von Cornelis Cort überlieferter Komposition "Herkules und Jolaos töten die lernäische Hydra" gegeben, wo der Held gleichfalls den zum Schlag erhobenen Arm vor dem Kopf hinwegführt - wie die Mänaden in den Dürer-Kompositionen und im Unterschied zu Renis Herkules senkt er dabei jedoch zugleich das Haupt, so daß sein Gesicht voll ansichtig ist; da ihm auch das Motiv des seitwärts gedrehten Leibes fehlt, scheint kaum ein Bezug zwischen diesem 1563 ausgeführten Stich und Renis Schöpfung zu bestehen; zu dem Floris-Gemälde vgl. Carl Van de Velde, Frans Floris (1519/20-1570) - Leven en Werken, Brüssel 1975, p. 218-227, Nos. 69-78; zu dem Cort-Stich vgl. J. C. J. Bierens de Haan, L'œuvre gravé de Cornelis Cort, graveur hollondais 1533-1578, La Haye 1948, p. 165f., No. 176 5).

$43 \mathrm{Zu}$ der Skulptur und ihrer Auffindung vgl. jüngst zusammenfassend Eugenio Polito, I Galati vinti, Mailand 1999 sowie Penny/Haskell (Anm. 32), p. 282ff., No. 68 und Beatrice Palma, Museo Nazionale Romano - Le sculture, Vol. I,4: I marmi Ludovisi: Storia della collezione, Rom 1983, wo p. 41 das Inventar vom 2. November 1623 zitiert wird, in dem die Gruppe als "une statua d'una donna morta con il padre che si ammazza da sè" geführt wird.

44 Hier abgebildet: der Nachstich von Johannes Episcopius (Jan de Bisshop), den er 1669 als Tafel 70 seinen Signorum veterum Icones, s.l.e.a. beifügte; zu dieser zwischen 1668 und 1669 in zwei Bänden durchgeführten Publikation vgl. Renske E. Jellema/Michiel Plomp, Episcopius - Jan de Bisshop (1628-1671): advocaat en tekenaar, Ausst.Kat. Amsterdam 1992, p. 47-57; wie Giulia Fusconi in 
ihrem Katalogbeitrag "La fortuna dei marmi Ludovisi nel Cinquecento e Seicento", in: Antonio Giuliano (Hrsg.), La collezione Boncampagni Ludovisi, Ausst. Kat. Rom 1992, p. 19-43, hier p. 40, richtig bemerkt, liegt dem 1676 von Richard Collin ausgeführten und 1676/79 in den 2. Hauptteil von Joachim von Sandrarts Academia Tedesca als Tafel c* aufgenommenen Nachstich der Gruppe eindeutig das Vorbild de Bisshops zugrunde.

45 Yves Bruand, "La restauration des sculptures antiques du cardinal Ludovisi", in: Mélanges d'archéologie et d'histoire, LXVIII, 1956, p. 397-418, insbes. p. 407 und 410 zufolge wurde die Statuengruppe - wie einige andere Antiken der Sammlung Ludovisi - von Ippolito Buzzi restauriert; da dieser am 7. April 1623 für seine Arbeiten bezahlt wurde, geht man von einer Auffindung der Gruppe während der Arbeiten am Bau der Villa Ludovisi am Jahresende 1622 aus; vgl. dazu auch zusammenfassend Palma (Anm. 43), p. 24 sowie p. 34 mit einem Abdruck der die Bezahlung Buzzis betreffenden Dokumente. Eine Kritik an den Restaurierungen Buzzis formuliert Margarete Bieber, The Sculpture of the Hellenistic Age, New York $1961^{2}$, p. 80, wo insbesondere der eben wohl von Reni rezipierte, vor dem Kopf des Galliers vorbeigeführte und sein Gesicht halb verdeckende Arm gerügt wird.

46 Pepper/Morselli (Anm. 1), p. 132f. beziehen die entsprechende Briefstelle auf eine hypothetische erste Fassung des "Nessus und Deianeira"-Bildes, die sie mit dem Exemplar in Prag (Narodny Gallery) identifizieren; ihnen zufolge wurde nach Abschluß der gesamten Bilderfolge im November 1622 eine neue, in der ersten Jahreshälfte 1623 ausgeführte und mit dem Gemälde im Louvre überlieferte Version der "Deianeira"-Szene bestellt, der die Erstfassung weichen mußte. Diese Hypothese steht und fällt jedoch nicht nur mit der stilkritisch begründeten, ein Jahr umfassenden Wegdatierung des LouvreBildes von den übrigen "Herkules"-Gemälden, sondern vor allem mit der Einschätzung des Prag-Exemplars, das Pepper 1988 (Anm. 31), p. 247 noch selbst als Werkstattarbeit beurteilt hatte (zur Bewertungsgeschichte des Bildes vgl. auch Loire 1996 [Anm. 5], p. 318, Anm. 13). Einwände gegen die Annahme von Pepper/Morselli (Anm. 1) erhebt schließlich auch Loire 1996 (Anm. 5), der sich p. 318 angesichts des Umstandes skeptisch äußert, daß der vermutete Bildertausch weder in Briefen noch in Inventaren irgendwelche Spuren hinterlassen haben soll. Auch haben die 1994 an der "Herkules"-Serie vorgenommenen Röntgenuntersuchungen - vgl. Loire 1996 (Anm. 5), p. 322, Anm. 15 - im Falle des "Deianeira"Bildes keine größeren Pentimenti zutage gefördert, die mit Barbazzis Bericht einer ganzen, komplett überarbeiteten Figur in Einklang zu bringen wären. Schließlich würde die von Pepper/Morselli vorgetragene Theorie noch immer diesen plötzlichen Sinneswandel Renis nicht erklären.

47 Im Falle des "Scheiterhaufen"-, insbesondere jedoch des "Hydra"-Gemäldes verliefen die oben (siehe vorangegangene Anm.) angeführten Röntgenuntersuchungen leider nahezu ergebnislos, da der zur Rentoilage benutzte Klebstoff die Aufnahmen bis zur Undurchsichtigkeit trübte: vgl. Loire 1996 (Anm. 5), p. 322, Anm. 15.

48 Borchhardt-Birbaumer 1991 (Anm. 32), p. 146, No. 20 und Daniel (Anm. 12), der p. 45 in Renis "Herkules" eine Amalgamierung von Torso und Laokoon verwirklicht sieht.

49 Während René Schneider, La peinture italienne du XVIe au XIX siècle, Paris/Brüssel 1930, p. 27, hierin gefolgt von Daniel (Anm. 12), p. 44, den ganzen Zyklus als eine "variation de talent sur le thème du Laocoon" betrachtete, schlagen Dückers (Anm. 37), p. 32, EbertSchifferer in: Frankfurt 1988 (Anm. 8), p. $125 \mathrm{ff}$. und BorchhardtBirbaumer 1991 (Anm. 32), p. 146, No. 20 die antike Figurengruppe als Vorbild für den "Herkules auf dem Scheiterhaufen" vor. Für eine Kritik an dieser Hypothese sowie dem daran von Ebert-Schifferer geknüpften "politisch-moralischen Gehalt" vgl. Donat de Chapeaurouge, "Guido Reni's 'Venus' und der 'Laokoon'”, in: Pantheon LVI, 1998, p. 108-109, hier p. 109, wo auch eine demgegenüber glaubwürdige Rückführung des "Venus"-Gemäldes in Toledo/Ohio auf den "Laokoon" vorgestellt wird.

50 Dückers (Anm. 37), p. 32; zu dem heute verlorenen und nur in einem auf ca. 1565 zu datierenden Nachstich Giulio Sanutos überlieferten Deckengemälde für Maria von Ungarn vgl. Harold E. Wethey, The Paintings of Titian, Vol. II: The Mythological and Historical Paintings, London 1975, p. 156ff., No. 19 C sowie zuletzt Sabine Tischer, Tizian und Maria von Ungarn - Der Zyklus der 'pene infernali auf Schloß Binche (1549), Peter Lang 1994, p. 53-55.

51 Vgl. dazu Johnston 1969 (Anm. 4), p. 72; zu den FarneseFresken Annibales vgl. John Rupert Martin, The Farnese Gallery, Princeton 1965, p. 31

52 Ursula Schlegel, "Bernini und Guido Reni", in: Jahrbuch der Berliner Museen, N.F., Vol. 27, 1985, p. 101-145, hier p.. 141f. sowie Valentino Martinelli in: L'Ariccia del Bernini, Ausst. Kat. Ariccia 1998, p. 121-124; zu den anderen Fassungen von Renis "Joseph" vgl. Pepper 1988 (Anm. 31), p. 340f., Nos. $48-50$ sowie p. 343, No. 63. Die Zeichnung Berninis wird diskutiert bei Heinrich Brauer/Rudolf Wittkower, Die Zeichnungen des Gianlorenzo Bernini, Berlin 1931, p. 154. Zu Renis Gemälde in New York vgl. Anm. 26.

53 Vgl. Paul Fréart de Chantelou, Journal de Voyage du Cavalier Bernin en France, mit den Anmerkungen von Ludovic Lalanne hrsg. von Jean Paul Guibbert, Clamecy 1981, p. 290 unter dem 16. Oktober 1665: "II m'a montré son académie qui est une figure en forme de captif, laquelle est belle et de ce que l'on dit de grandre manière." Bereits 1885 assoziierte Lalanne - in der Folge von Brauer/Wittkower (Anm. 52), p. 152, Anm. 5 und Martinelli, p. 177 (siehe folgende Anm.) zustimmend übernommen - diese Beschreibung mit dem Blatt im Louvre.

54 Paris, Louvre, 9585; zu dieser Zeichnung, erstmals publiziert von Valentino Martinelli, "I disegni del Bernini", in: Commentari, I, 1950, p. 172-186, hier p. 177f., Tafel LXIV, vgl. auch Brauer/Wittkower (Anm. 52), p. 152, Anm. 5, wo das Blatt als "ohne Zweifel original" geführt wird, sowie p. 163, wo die Weiterentwicklung der dort fixierten Pose im Rahmen eines Entwurfs für einen Kaminbock verfolgt wird.

55 Martinelli (Anm. 54), p. 177 interpretiert die Figur eher als einen steinschleudernden David, was angesichts von dessen wilder Haar- und Barttracht wenig überzeugend anmutet. Auf eine weitere, kuriose Rezeption von Renis Herkules durch den englischen Anatomen William Cowper (1666-1709/10) hat Monique Kornell aufmerksam gemacht: in ihrem Beitrag zu dem Katalog The Ingenious Machine of Nature, Ottawa 1996, p. 186-188, No. 72 weist sie den hydratötenden Helden als direkte Vorlage eines auf ca. 1705/10 zu datierenden Frontispizentwurfs (Glasgow University Library) Cowpers für dessen "Myotomia reformata or An Anatomical Treatise on the Muscles of the Human Body" nach. Überdeutlich schließlich Christoph Unterpergers Rezeption, der die Pose von Renis Protagonisten für sein Gemälde "Herkules und Lichas" adaptiert vgl. dazu Susanna Petereit Guicciardi in Cristoforo Unterperger: un pittore fiemmese nell'Europa del Settecento, Ausst.Kat. Rom 1998 hrsg. von Chiara Felicetti, wo p. 90f. (Anm. 31) auch auf Pietro da Cortonas Übernahme verwiesen wird, sowie ebd., p. 203-208, Nos. 96103.

56 Zu dem Faun vgl. Guida illustrata del Museo Nazionale di Napoli, hrsg. von A. Ruesch, 2 Vols., Neapel 1911, Vol. I, p. 214, No. 858 (5628) sowie Wilhelm Klein, Vom antiken Rokoko, Wien 1921, p. 44f.; für den in Repliken, Kopien und Darstellungen offenbar weitverbreiteten Prototypen dieses Fauns wird eine Herkunft aus dem perga- 
menischem Umfeld Kleinasiens der Zeit um das 2. Jahrhundert v. Chr. angenommen. Für die fünf Jahre nach Auffindung der Skulptur erfolgte und 1759 abgeschlossene Restaurierung durch Tommaso Valenziano vgl. Tiziano Caianiello, "Restauratori di sculture antiche a Portici”, in: Dialoghi di storia dell'arte, No. 6, 1998, p. 54-69, hier besonders p. 62

57 Interessanterweise assoziiert Martinelli (Anm. 54), p. 177 die oben besprochene Louvre-Variation auf den hydratötenden Herkules stilistisch wie typologisch mit Berninis Figural-Studien zum Vierströmebrunnen, die er je als "accademie" anspricht. Rudolf Preimesberger, "Obeliscus Pamphilius - Beiträge zu Vorgeschichte und Ikonographie des Vierströmebrunnens auf Piazza Navona", in: Münchner Jahrbuch der bildenden Kunst, XXV, 1974, p. 77-162, hier p. 132 folgend, hätte Bernini somit die Übermuts-Gebärde des antiken Faunes zu einem klassischen, auch das Erschrecken umfassenden Akklamationsgestus umgedeutet. Zu Berninis zwischen 1648 und 1651 errichtetem Brunnen vgl. Rudolf Wittkower, Bernini - Lo scultore del Barocco romano, Mailand 1990, p. 176f. sowie p. 269f., No. 50. Der Rio della Plata wurde zwischen 1650/51 von Francesco Baratto nach dem Bozzetto Berninis (Venedig, Museo Marciano/Ca d'Oro) ausgeführt; zu diesem vgl. A. E. Brinckmann, Barock-Bozzett (Italienische Bildhauer), Vol. II, Frankfurt/Main 1923, p. 44-47. Eine erste, bereits einige Motive des Faunes spiegelverkehrt andeutende Studie (vgl. den zur Seite gedrehten und in die Schulter gebetteten Kopf, das Zusammenspiel der erhobenen und gesenkten Arme sowie der angewinkelten und ausgestreckten Beine) ist mit einer Zeichnung aus den Uffizien (Inv. 11921) erhalten. Zu dieser Zeichnung vgl. Brauer-Wittkower (Anm. 52), p. 50. No. 31, wo dem Blatt der Charakter einer Akademiestudie zuerkannt wird. Wie Götz Pochat, "Über Berninis 'Concetto' zum Vierströmebrunnen auf Piazza Navona", in: Konsthistorisk Tidskrift, XXXV, 1966, p. 72-79, hier p. 73 und Preimesberger (s.o.), p. 132 richtig bemerken, steht dieses Blatt auf halbem Wege zwischen dem Bozzetto der Gesamtanlage (Rom, E. Sestieri: vgl. Brinkmann [s.o.], p. 40) und der Endredaktion, die (Preimesberger [s.o.], p. 131) "monumentalisiert und den antiken Prototypen zumindest generell genähert” erscheint. Auch Hans Kauffmann, Giovanni Lorenzo Bernini - Die figürlichen Kompositionen, Berlin 1970 betont, (p. 186) daß Bernini sich "erst in diesen vier Flußgöttern (...) von konventionellen Posen freigemacht" und sie (p. 192) "wie keinmal zuvor (...) antiken Flußgöttern angeähnelt" hat, wobei er zugleich auf ihr "heidnisches, richtiger ihr dämonisches Wesen" aufmerksam macht. Daß sowohl die Florentiner Studie als auch insbesondere diese Endfassung sich der von einer Antike vermittelten Anregung verdankt, bestätigt einmal mehr die von Norbert Huse, Gianlorenzo Berninis Vierströmebrunnen (Diss.), München 1967, p. 18 getätigte Feststellung "Die Motive, denen Bernini sich bediente, sind zum Teil früheren Kunstwerken entlehnt." Zu den anderen, sich Michelangelo zum Vorbild nehmenden Motiven vgl. Huse, p. $51 \mathrm{ff}$.

58 Vgl. als ein die weite Verbreitung dieses Fauntyps dokumentierendes Beispiel das 1947 gefundene Exemplar im Museo Nazionale Romano in Rom: Antonio Giuliano (Hrsg.), Museo Nazionale Romano - Le sculture, Vol. I,1, Rom 1979, p. 99f., No. 76.

59 Eine Münze aus Nikaia in Bythnien aus der Zeit des Commodus, erworben 1865 bei dem Münzhändler Paul Lambros in Athen: vgl. dazu Julius Friedländer, "Neue Erwerbungen des $\mathrm{K}$. Münzkabinetts", in: Archäologische Zeitung, N.F. II, XXVII, Berlin 1869 , p. $97-104$, hier p. 97 (1. Stück) und Tafel 23,1 sowie W.H Waddington/E. Babelon/Th. Reinach: Recueil général des monnaies greques d'Asie mineure, Vol. I,3, Paris 1910, p. 430, No. 243, Tafe LXXIII,13 und M. Bernhart, "Dionysos und seine Familie auf griechi- schen Münzen", in: Jahrbuch für Numismatik und Geldgeschichte, I, 1949, p. 159, No. 1354, Tafel X,27 (meinen herzlichen Dank an H.-D. Schultz vom Berliner Münzkabinett, der mich in einem Brief vom 9. Januar 1996 mit ausführlichen Informationen zu der Münze versorgte). $\mathrm{Zu}$ anderen, von Bernini für Motive des Brunnens konsultierten antiken Münzen vgl. Preimesberger (Anm. 57), p. 131. Weiteren Niederschlag scheint die Figur des Faunes je in den Kompositionen Giovan Battista Gaullis ("II Beato Giovanni Chigi nel deserto", Ariccia: Palazzo Chigi) und Orazio Riminaldis ("Prometheus", Tours: Musée des Beaux-Arts - bezeichnenderweise einst auch Reni selbst zugeschrieben) gefunden zu haben; zu diesen Gemälden vgl. Almamaria Mignosi Tantillo in: L'Ariccia del Bernini (Anm. 52), p. 150-152 und Annie Gilet (Hrsg.), Italies - Peintures des musées de la région Centre, Ausst. Kat. Paris 1996, p. 186ff., No. 50.

$60 \mathrm{Vgl}$. Anton Springer, Raffael und Michelangelo, Vol. I, Leipzig 1883, p. 40 (Fig. 13) und p. 42.

61 Alfred Stix/Anna Spitzmüller, Beschreibender Katalog der Handzeichnungen - Albertina, Vol. VI: Schulen von Ferrara, Bologna..., Wien 1941, p. 9, No. 57; die dort vorgenommene Zuschreibung kürzlich bestätigt durch Veronika Birke/Janine Kertész, Die italienischen Zeichnungen der Albertina, Böhlau (Wien/Köln/Weimar) 1992, Generalverzeichnis, Vol. I, Inv. 1-1200, p. 74, Inv. 131. Die Identifizierung A. Grünwalds, der in der Zeichnung eine Wiedergabe des Faunes erkannte, hat erstaunlicherweise in keinen der Wiener Kataloge Eingang gefunden, wo die Motive des Blattes stets als "Aktstudien" (Stix/Spitzmüller) bzw. "Halbakte in Drehbewegung" (Birke/Kertész) beschrieben werden; die Beobachtung Grünwalds ist mitgeteilt in: Wilhelm Klein, Geschichte der griechischen Kunst, Leipzig 1907, III, p. 243, Anm. 2.

62 Vgl. z.B. das Exemplar im Besitz der Münchner Glyptothek (München 224), das heute im Pompejanum in Aschaffenburg ausgestellt wird - siehe dazu A. Furtwängler, Hundert Tafeln - Illustrierter Katalog, München 1903, p. 43, Tafel 68; in einem Brief vom 25. September 1996 war Vinzenz Brinkmann von der Münchner Glyptothek so freundlich, mich über die dokumentierte Erwerbsgeschichte der Skulptur zu informieren: sie stammt aus der Sammlung Albani, wurde unter Napoleon nach Paris verbracht und dort 1815 auf einer Versteigerung für das bayerische Königshaus erworben.

63 Florenz, Uffizien, Inv. 12611 F; vgl. dazu Johnston 1969 (Anm. 4), p. 73 sowie Catherine Johnston, The Drawings of Guido Reni, Ph.D. thesis, 1974, p. 141f., No. 105.

64 Vgl. die von Malvasia, Felsina Pittrice (Anm. 27), Vol. I, p. 188 gelieferte Beschreibung der Sammlung Passerotti: “(...) quantità di romani rilievi, infinità d'antiche medaglie, numerosità di libri singolari (...) ed altre cose impietrite, idoletti, camei, gioie e simili curiosità" sowie die ebendort gegebenen Zeugnisse ihrer Berühmtheit: "(...) onde non era Legato, che Bologna governasse, non personaggio grande, che per quella passasse, non forestiero che vi si trattenesse, o che da essa partisse, senza aver prima veduto ed ammirato i duo studii famosi a que' tempi, cioè quello di Cammillo Bolognini e quello de' Passerotti." Vgl. diesbezüglich insbesondere Angela Ghirardi, Bartolomeo Passerotti - Pittore (1529-1592), Rimini 1990, p. 34-48 sowie Maria Luigia Pagliani, "Guido Reni (1575-1642): Percorsi nell'antico", in: Accdemia Clementina. Atti e Memorie, No. 25, 1990, p. $155-163$, hier p. 157. Zur Antikenkultur in den bolognesischen Sammlungen dieser Zeit vgl. generell Anna Maria Brizzolara, "II museo di Ulisse Aldrovandi", in: Dalla stanza della Antichità al Museo Civico - Storia della formazione del Museo Civico Archeologico di Bologna, Ausst. Kat. Bologna 1984, p. 119-124; Sandro de Maria: "Artisti, 'antiquari' e collezionisti di antichità a Bologna fra XV e XVI secolo", in: 
Bologna e l'umanesimo 1490-1510, Ausst.Kat. Bologna 1988, p. 17-42 und Claudio Franzoni, "'Rimembranze d'infinite cose' - Le collezioni rinascimentali di antichità", in: Memoria dell'antico nell'arte italiana, hrsg. von Salvatore Settis, Turin 1984, I, p. 298-360, hier p. 327.

$65 \mathrm{Vgl}$. zu diesem früher Pietro Testa zugeschriebenen Studienblatt aus der Graphischen Sammlung in München (Inv. 3000) Johnston 1969 (Anm. 4), p. 72 sowie Johnston 1974 (Anm. 63), p. 136f., No. 103, die ebd., p. 137 eine Abhängigkeit zwischen Renis Zeichnung und der Pose des Neptun in Pellegrino Tibaldis PoggiFresken in Bologna sieht — tatsächlich jedoch gilt auch hier das oben bezüglich der Torso- und Laokoon-Vergleiche Gesagte, teilt sich Tibaldis Figur mit Renis Herkules doch lediglich den mächtigen Leib und die Positionen der Arme, während die Lagerung beider Gestalten je unterschiedlich konzipiert ist: liegt der Neptun, seinen Oberkörper und Unterarm auf ein Kissen gestützt, auf einer Ruhestatt, so reckt Renis Figur ihren Oberkörper gerade in die Höhe.

66 Zu Renis grundsätzlicher Gewohnheit, eigene Kompositionen in Form von Repliken und Varianten zu wiederholen, vgl. D. Stephen Pepper, "Guido Reni's Practice of Repeating Compositions", in: Artibus et Historiae, No. 39 (XX), 1999, p. 27-54

67 Brenna (Anm. 39), p. 152; zu dem Gemälde vgl. Sybille EbertSchifferer in: Frankfurt 1988 (Anm. 8), p. 129ff., No. A 6.

68 Paris, Louvre, Cabinet des Dessins, Inv. 8917; vgl. dazu Johnston 1974 (Anm.63), p. 173f., No. 141 und Birke 1981 (Anm. 11), p. 126 , No. 87 , die gleichfalls je die Ähnlichkeiten zwischen der Herkules- und der Marsyas-Pose betonen.

69 Zu dem Gemälde vgl. Pepper 1988 (Anm. 31), p. 249, No. 73.

70 Bellori (Anm. 29), p. 529. 